\title{
Vibration-Based Damage Assessment in Gravity-Based Wind Turbine Tower under Various Waves
}

\author{
Cong-Uy Nguyen, ${ }^{1}$ So-Young Lee, ${ }^{2}$ Heon-Tae Kim, ${ }^{3}$ and Jeong-Tae Kim ${ }^{3}{ }^{3}$ \\ ${ }^{1}$ Graduate Student, Department of Ocean Engineering, Pukyong National University, Busan, Republic of Korea \\ ${ }^{2}$ Post-Doctoral Researcher, Department of Ocean Engineering, Pukyong National University, Busan, Republic of Korea \\ ${ }^{3}$ Professor, Department of Ocean Engineering, Pukyong National University, Busan, Republic of Korea
}

Correspondence should be addressed to Jeong-Tae Kim; idis@pknu.ac.kr

Received 8 March 2019; Revised 19 April 2019; Accepted 30 April 2019; Published 23 May 2019

Academic Editor: Stefano Marchesiello

Copyright ( $\odot 2019$ Cong-Uy Nguyen et al. This is an open access article distributed under the Creative Commons Attribution License, which permits unrestricted use, distribution, and reproduction in any medium, provided the original work is properly cited.

\begin{abstract}
In this study, the feasibility of vibration-based damage assessment in a wind turbine tower (WTT) with gravity-based foundation (GBF) under various waves is numerically investigated. Firstly, a finite element model is constructed for the GBF WTT which consists of a tower, caisson, and foundation bed. Eigenvalue analysis is performed to identify a few vibration modes of interest, which represent complex behaviors of a flexible tower, rigid caisson, and deformable foundation. Secondly, wave-induced dynamic pressures are analyzed for a few selected wave conditions and damage scenarios are also designed to simulate the main components of the target GBF WTT. Thirdly, forced vibration responses of the GBF WTT are analyzed for the wave-induced excitation. Then modal parameters (i.e., natural frequencies and mode shapes) are extracted by using a combined use of timedomain and frequency-domain modal identification methods. Finally, the variation of modal parameters is estimated by measuring relative changes in natural frequencies and mode shapes in order to quantify the damage-induced effects. Also, the wave-induced variation of modal parameters is estimated to relatively assess the effect of various wave actions on the damageinduced variation of modal parameters.
\end{abstract}

\section{Introduction}

The wind turbine tower (WTT) with gravity-based foundation (GBF) has three main subsystems such as tower, caisson, and foundation bed [1]. The flexible tower consists of segmental slender columns fastened by bolted flanges and a rotor operating nacelle on its top. The rigid caisson consists of a hollow concrete container and infill aggregates to support the tower on its top and to carry external forces into the foundation bed. The deformable foundation bed includes gravel mound, backfill layer, and natural ground to resist against the external forces and energies transmitted from the tower and the caisson. Under the severe operating environment, the GBF WTT experiences extreme forces such as typhoon and earthquake which may endanger the safety of the system.

The integrity of the structure-foundation system gets into danger when extreme loadings mix with local damage in critical subsystems. The worst scenario is that those unwanted situations mix with the inborn characteristics such as heavy self-weight and blade rotation-induced dynamic loading $[2,3]$. Therefore, it should be noticed that a variety of local damage types can occur in the subsystems. The slender tower damages as similar as local buckling, crack, or bolt loosening in segmental joints. The wave impact coupled with the armor stone can cause local damage like crack or hole in the concrete caisson, which results in the loss of infill sand. The heavy self-weight may create the settlement of the seabed, and the severe wave condition may create the local scouring in the caisson foundation [4].

Local damage that occurs in the subsystems (e.g., tower, caisson, and foundation) leads to the change of structural design parameters such as stiffness, mass, and damping, which consequently result in the change of vibration characteristics of the GBF WTT [5-8]. Over the left, it is greatly important to utilize the vibration characteristics for 
assessing local damage and global integrity of the entire system [9-12]. However, there are a few technical obstacles to measure vibration responses for assessing damage in the GBF WTT. A major concern is to monitor vibration responses of the mostly submerged system under restricted conditions of sensor placement and excitation source. Lee et al. [13] have made a research effort to locally measure wave-induced acceleration signals from the top of caisson and to interpret its responses related to the entire structural system including the submerged caisson and foundation properties.

Another major issue is to quantify relative effects of local damage and wave action on the change of global vibration characteristics $[5,14]$. Potential damage types in the subsystems may include local stiffness loss of tower, mass change of concrete caisson, and foundation damage such as scour. The variation of vibration characteristics would be dependent on each damage type. Also, the vibration characteristics of the GBF WTT would be changed under various waves which produce various excitations into the structure. Therefore, the effect of uncontrollable wave conditions on the vibration characteristics should be investigated to make sure of damage assessment results from the wave-induced vibration responses.

In this study, the feasibility of vibration-based damage assessment in GBF WTT under various waves is numerically investigated. Firstly, a finite element (FE) model of GBF WTT is generated. A few vibration modes, which represent complex behaviors of flexible tower, rigid caisson, and deformable foundation, are identified by eigenvalue analysis. Secondly, wave-induced dynamic pressures are analyzed for a few selected waves. Damage scenarios which include damages on tower, caisson, and foundation are also designed to simulate main components of the target GBF WTT. The wave pressures are applied to the FE model of GBF WTT. Then modal parameters are extracted by using a combined use of time-domain and frequency-domain modal identification methods. Finally, damage-induced effects are quantified from investigation of relative changes in natural frequencies and mode shapes. Also, the effect of various wave actions on the damage-induced variation of modal parameters is assessed by the estimation of wave-induced variation of modal parameters.

\section{Description of Target GBF WTT}

2.1. Numerical Modeling of Target GBF WTT. A gravitybased foundation (GBF) wind turbine tower (WTT) consists of three main components which are tower, caisson, and foundation bed. A GBF WTT of 3.0 MW capacity was selected as the target structure, as shown in Figure 1. The geometry was based on Hankyung II Wind Park at Jeju Island, Korea $[15,16]$. The WTT was assumed as partially submerged under the still water level of $13.69 \mathrm{~m}$. The superstructure consists of a steel tubular tower, three blades of 6.6 ton, a nacelle of 68 ton, and a rotor of 20 ton. The tower has three main segments including one segment of $19.3 \mathrm{~m}$ and two segments of $29 \mathrm{~m}$ fabricated by bolted flanges. Each main segment was formed by several sections with thickness changing along with the elevation, as outlined in Table 1 . The tower's top and bottom diameters were $2.316 \mathrm{~m}$ and $4.150 \mathrm{~m}$, respectively.

As shown in Figure 1(b), the caisson consists of tubular and conical parts with infill aggregates. The geometric shape was roughly scaled down with a factor of 0.75 from a design example of offshore wind turbine supporting structure [17]. An anchor had the height of $1.2 \mathrm{~m}$ and the thickness of $0.95 \mathrm{~m}$, and it was designed on top of the tube part to connect the caisson with the tower. In the caisson, a stiffener had the height of $0.75 \mathrm{~m}$ and the thickness of $0.75 \mathrm{~m}$, and it was located between the tube and conical part. As shown in Figure 1(c), the foundation consists of a scour protection layer, backfill layer, gravel, and filter layers above natural ground. The geometry was designed on the basis of an example from Thornton Bank Offshore Wind Farm [18-20]. The domain of the foundation bed was selected as four times of the bottom diameter of the caisson. Individual components of the foundation bed were simulated as indicated in Figure 1(c). Material properties of all components of the GBF WTT are outlined in Table 2.

2.2. FE Model of Target GBF WTT. The wind turbine tower with the varying thickness (as listed in Table 1) was modeled by using shell elements, as shown in Figure 2. Along the perimeter, 36 elements were meshed at every section to maintain continuity in the FE model. Each shell element has $1 / 5$ for width-to-height ratio. Four flanges connecting main segments were also modeled by using the shell elements. The rotor and nacelle on the top were simplified as two lump mass elements linked rigidly to the top flange of the tower (Figure 2(a)). The distance from the masses of the rotor and the nacelle to the center of the tower is $1.8 \mathrm{~m}$ and $4.8 \mathrm{~m}$, respectively. The caisson foundation was modeled by using two element types: shell elements for concrete wall and solid elements for infill sand. To consider the submerged condition of the caisson foundation, the effective mass of seawater $M_{\mathrm{w}}$ was simulated on the basis of Westergaard's equation of hydrodynamic water pressure [21]:

$$
M_{\mathrm{w}}=\int_{h_{1}}^{h_{2}} \frac{7}{8} \rho_{\mathrm{w}} \sqrt{H_{\mathrm{w}} h} d h,
$$

where $M_{\mathrm{w}}$ is the hydrodynamic mass, $\rho_{\mathrm{w}}$ is the seawater density of $1027 \mathrm{~kg} / \mathrm{m}^{3}, H_{\mathrm{w}}$ is the depth from the water level to the foundation, and $h$ is the water level to the point of hydrodynamic pressure. For 36 vertical planes, the added masses were calculated via the integration along the elevation.

The scour protection layer was modeled as added mass elements. All other layers in the foundation bed and the natural ground (i.e., $13 \mathrm{~m}$ depth assigned in Figure 1) were simulated using solid elements. The caisson and the scour protection layer are rigidly connected and the nodes are shared for contact surface between them. The remainders of the natural ground were modeled by using translational springs by assigning to bottom nodes and surrounding surfaces of the FE model. The $x$-, $y$-, and $z$-directional spring constants (i.e., $k_{x}, k_{y}$, and $k_{z}$ ) were computed by multiplying 


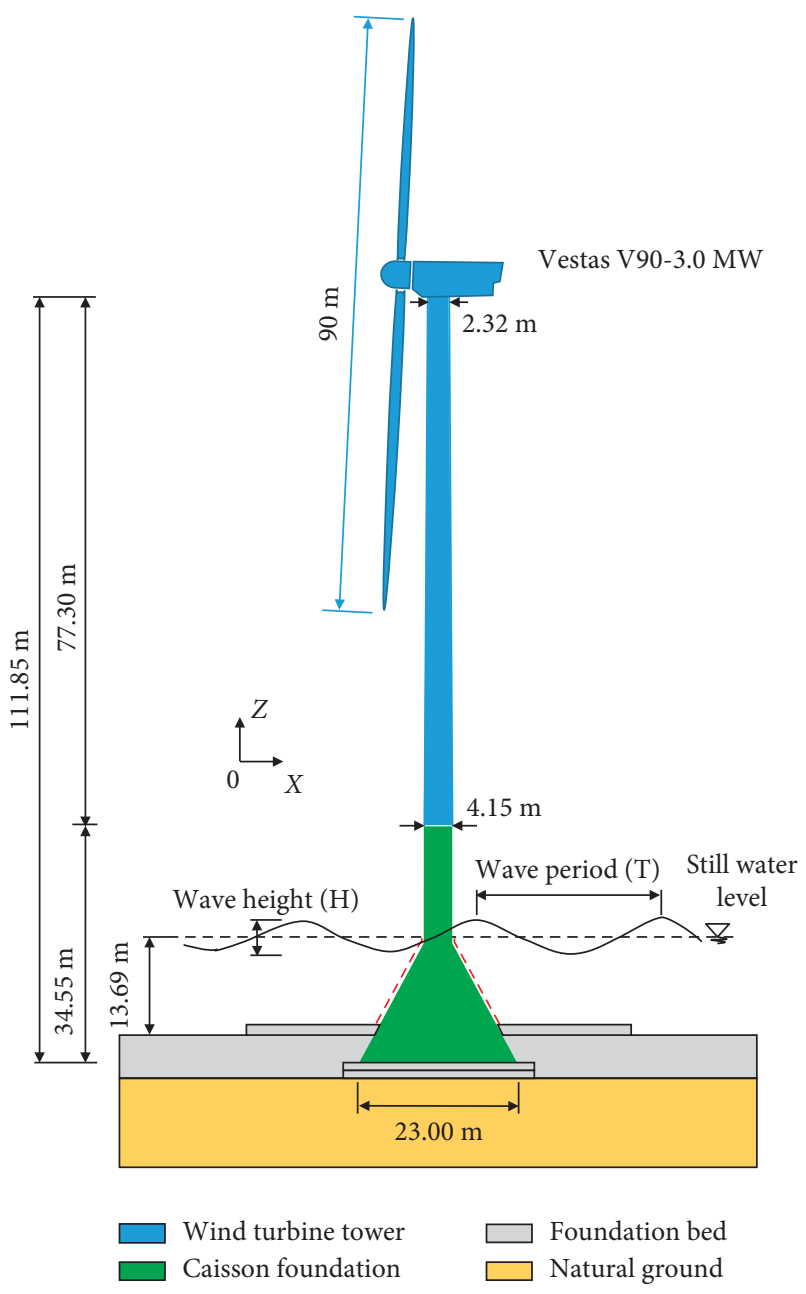

(a)

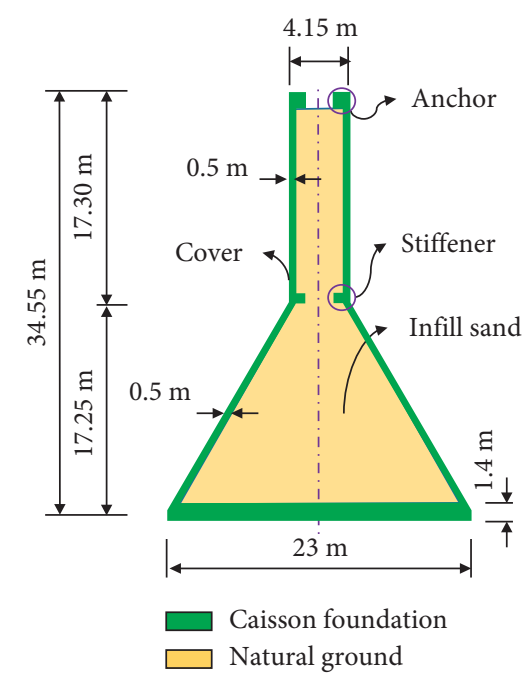

(b)

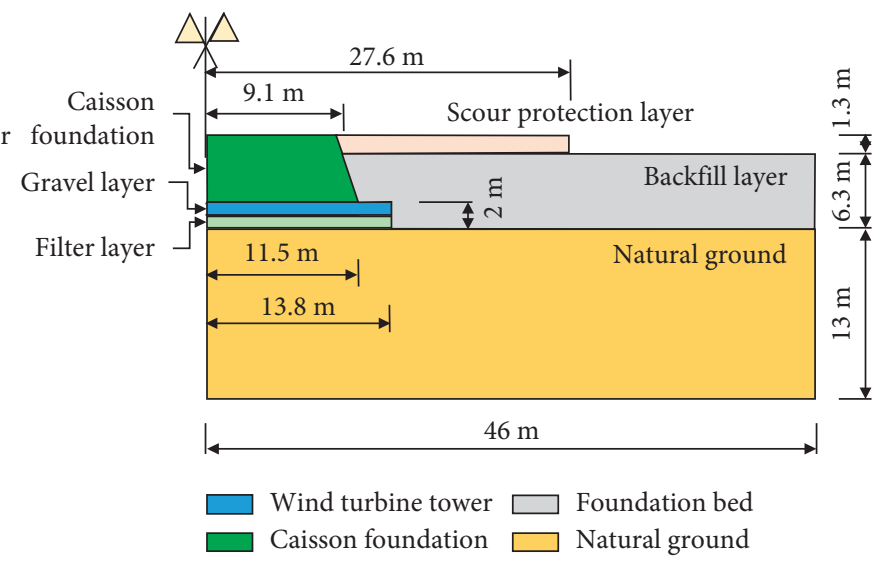

(c)

Figure 1: Geometry of target GBF WTT. (a) Lateral view of GBF WTT. (b) Caisson. (c) Foundation.

TABLE 1: Cross-sectional thickness of the wind turbine tower [16].

\begin{tabular}{lccc}
\hline Height $(\mathrm{m})$ & Thickness $(\mathrm{mm})$ & Height $(\mathrm{m})$ & Thickness $(\mathrm{mm})$ \\
\hline $0 \sim 5.4$ & 40 & $42.2 \sim 50.9$ & 21 \\
$5.4 \sim 21.9$ & 26 & $50.9 \sim 53.8$ & 19 \\
$21.9 \sim 30.6$ & 24 & $53.8 \sim 56.7$ & 18 \\
$30.6 \sim 36.4$ & 23 & $56.7 \sim 59.6$ & 17 \\
$36.4 \sim 42.2$ & 22 & $59.6 \sim 77.3$ & 16 \\
\hline
\end{tabular}

TABLE 2: Material properties of the wind turbine tower with caisson foundation.

\begin{tabular}{|c|c|c|c|c|}
\hline Structural component & Material type & Modulus of elasticity, E (MPa) & Poisson's ratio, $U$ & Mass density, $\rho\left(\mathrm{kg} / \mathrm{m}^{3}\right)$ \\
\hline Wind turbine tower ${ }^{\mathrm{a}}$ & Steel & $2.10 E+05$ & 0.3 & 7698 \\
\hline \multirow{2}{*}{ Caisson foundation $^{\mathrm{b}}$} & Concrete & $3.35 E+04$ & 0.2 & 2500 \\
\hline & Infill sand & 66.5 & 0.325 & 1620 \\
\hline \multirow{4}{*}{ Foundation bed ${ }^{\mathrm{c}}$} & Scour protection layer & - & - & 1800 \\
\hline & Backfill layer & 66.5 & 0.325 & 1620 \\
\hline & Gravel layer & 140 & 0.3 & 1500 \\
\hline & Filter layer & 140 & 0.3 & 2100 \\
\hline Natural ground $^{\mathrm{c}}$ & Sand layer & 66.5 & 0.325 & 1620 \\
\hline
\end{tabular}

${ }^{\mathrm{a}}$ Nguyen et al. [16]; ${ }^{\mathrm{b}}$ Daewoo E\&C [17]; ${ }^{\mathrm{c}}$ Lee et al. [13].

elastic compressive coefficients (e.g., $C_{\mathrm{z}}=7.5 \mathrm{~kg} / \mathrm{cm} / \mathrm{cm}^{2}$ and $C_{x}=C_{y}=3.75 \mathrm{~kg} / \mathrm{cm} / \mathrm{cm}^{2}$ for sand) with supported area [22]. An array of pseudosensors was simulated by equally distributing along the tower, as shown in Figure 2(b). Considering the water level and potential wave heights, Sensor 1 was placed at $30.24 \mathrm{~m}$ height from the foundation 


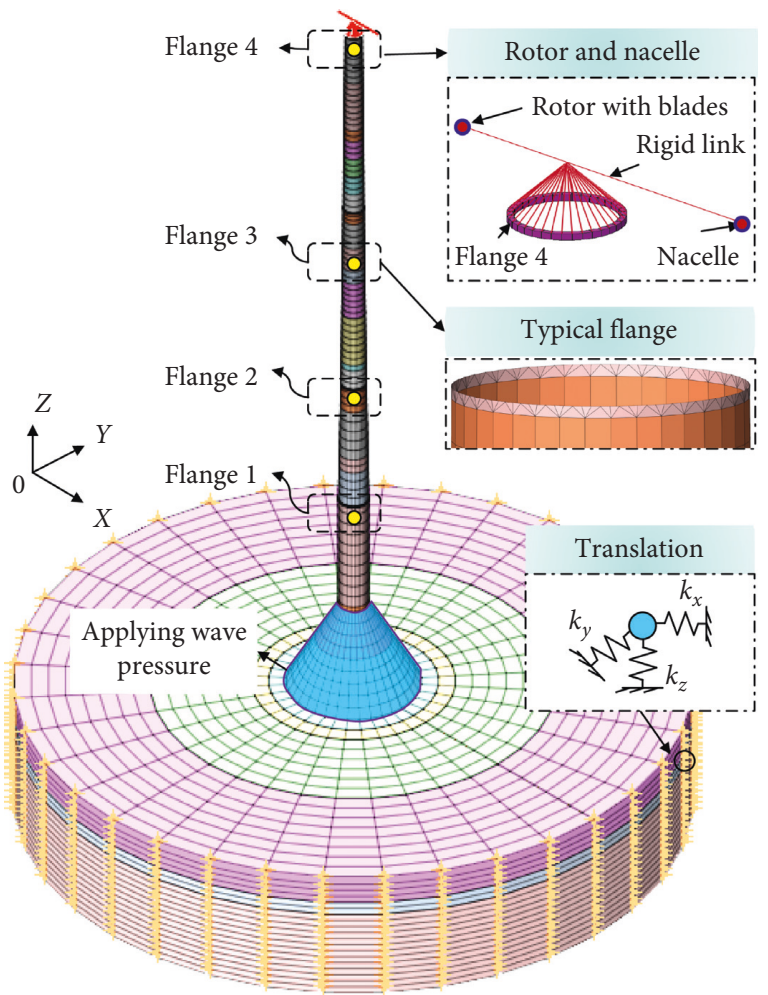

(a)

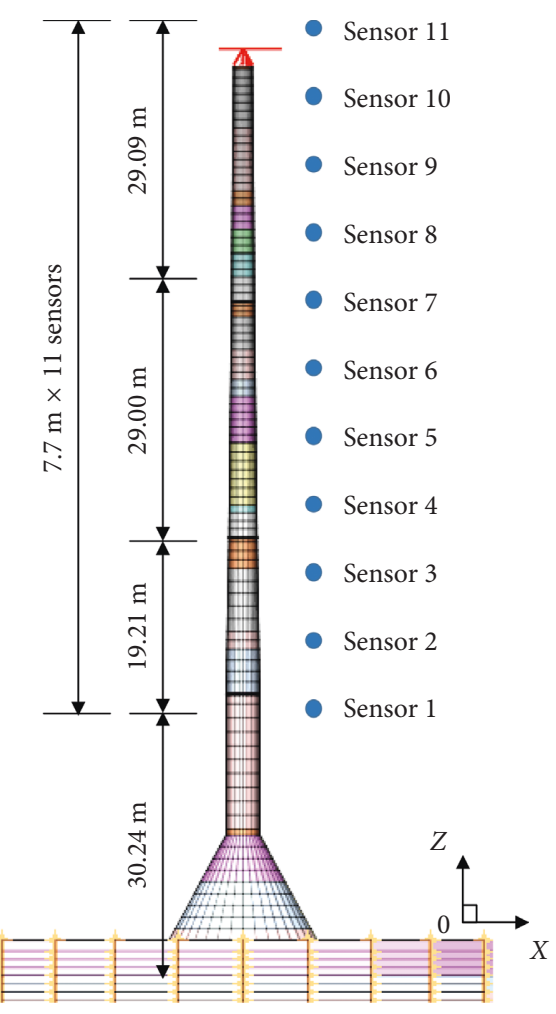

(b)

FIgURE 2: FE model of the wind turbine tower with caisson foundation. (a) FE model. (b) Sensor location.

bed. Totally 11 pseudosensors were assigned to obtain acceleration responses, from which flexural vibration modes were extracted for the target structure.

2.3. Eigenvalue Analysis of FE Model. Eigenvalue analyses were performed to identify natural vibration characteristics of the FE model of the GBF WTT. As described in Table 3 (and also shown in Figures 3 and 4), totally six natural vibration modes were analyzed for the GBF WTT, including three along-wave directional bending modes and three across-wave directional bending modes. All modes represent modal motions of the flexible tower, the rigid caisson, and the deformable foundation. Natural frequencies of the six modes were summarized in Table 3 . The tower's motions can be classified as bending with respect to $x$-axis or $y$-axis.

Based on the tower's motions, three along-wave directional bending modes (i.e., flexural motions with respect to $x$-axis) were analyzed as shown in Figure 3 . Modes Bx1, $\mathrm{Bx} 2$, and $\mathrm{Bx} 3$ were found at $0.2830 \mathrm{~Hz}, 1.5619 \mathrm{~Hz}$, and $2.4006 \mathrm{~Hz}$, respectively. Also, three across-wave directional bending modes (i.e., flexural motions with respect to $y$-axis) were analyzed as shown in Figure 4. Modes By1, By2, and By3 were found at $0.2840 \mathrm{~Hz}, 1.5897 \mathrm{~Hz}$, and $2.4576 \mathrm{~Hz}$, respectively. It is observed that the tower's flexural motions were identified along with the foundation's deformable motions.

As described in Figure 2(a), wind turbine blades were considered as lumped mass with the rotor. Eigenvalue analysis of the blades-detailed FE model was conducted to
TABLE 3: Natural frequencies of free vibration modes.

\begin{tabular}{llc}
\hline Order & $f(\mathrm{~Hz})$ & Description \\
\hline 1 & 0.2830 & Mode Bx1: 1st bending about $x$-axis \\
2 & 0.2840 & Mode By1: 1st bending about $y$-axis \\
3 & 1.5619 & Mode Bx2: 2nd bending about $x$-axis \\
4 & 1.5897 & Mode By2: 2nd bending about $y$-axis \\
5 & 2.4006 & Mode Bx3: 3rd bending about $x$-axis \\
6 & 2.4576 & Mode By3: 3rd bending about $y$-axis \\
\hline
\end{tabular}

investigate modal characteristics with respect to the orientation of the blades. The blades were considered as lumped masses with rigid link elements for each blade as described in Figure 5(a).

The eigenvalues of the blades-detailed FE model were examined. Three types of orientation were considered as shown in Figure 5(b). Six eigenvalues for Modes Bx1-3 and Modes By1-3 were resulted as follows: $0.307963 \mathrm{~Hz}, 1.57009 \mathrm{~Hz}$, $1.85594 \mathrm{~Hz}, 0.309149 \mathrm{~Hz}, 1.595 \mathrm{~Hz}$, and $1.88696 \mathrm{~Hz}$. The differences in eigenvalues between the blades-simplified model and the blades-detailed model were examined. The amount of differences was $8.8 \%$ in Modes Bx1 and By1, 0.3 0.5\% in Modes Bx2 and By2, and 0.2 0.3\% in Modes Bx3 and By3. The effect of the way to considering the blades on eigenvalues were larger in lower modes. Variation of the eigenvalues with respect to the orientation of blades was not found in five decimal places. Therefore, the effect of the orientation of blades on modal characteristics is very small. Note that the dynamic effects of blades' movement resulted by operating the wind turbine tower were not considered in this study. 


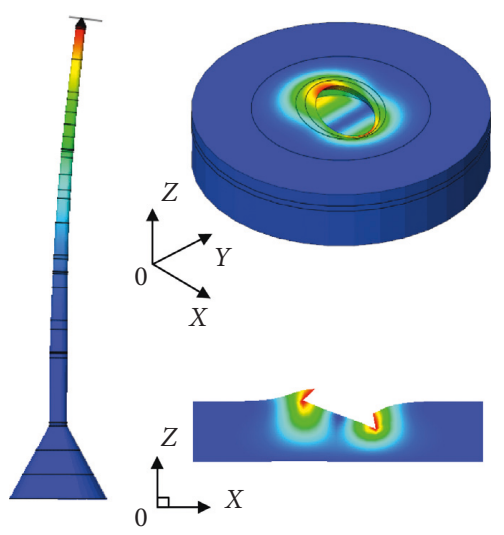

(a)
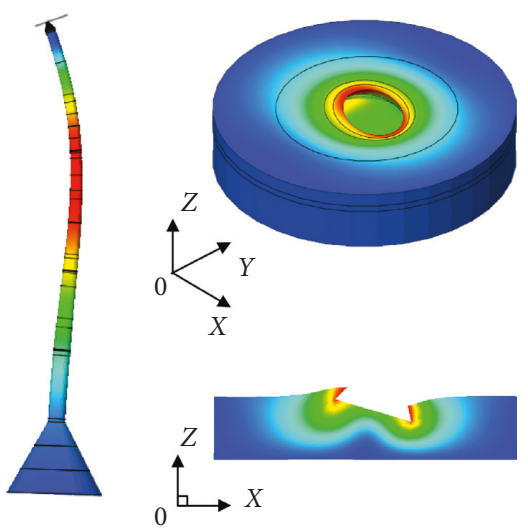

(b)
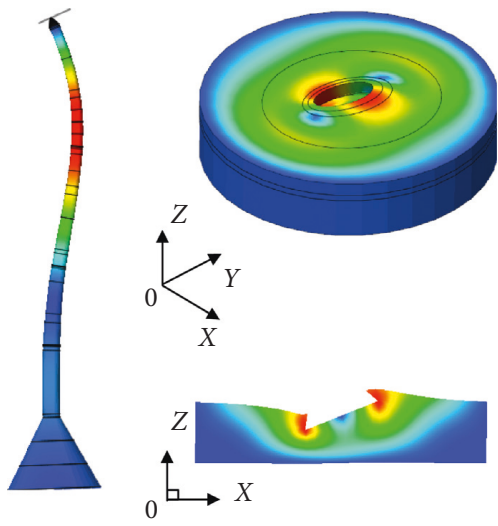

(c)

Figure 3: Along-wave directional bending modes from eigenvalue analysis. (a) Mode Bx1 (0.2830 Hz). (b) Mode Bx2 (1.5619 Hz). (c) Mode Bx3 $(2.4006 \mathrm{~Hz})$.

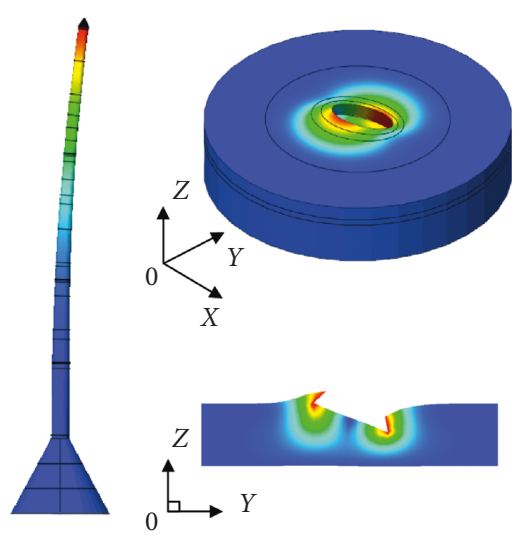

(a)
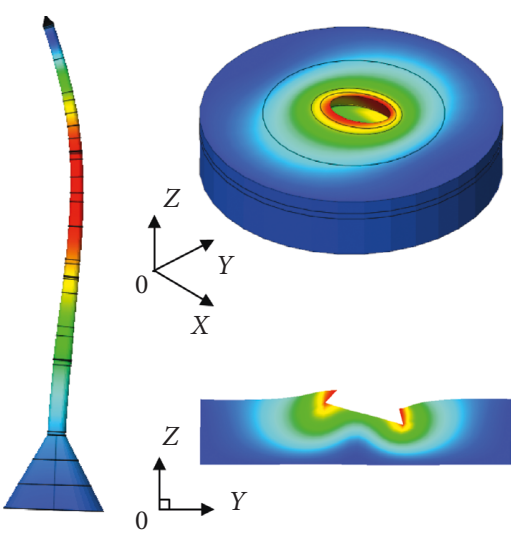

(b)
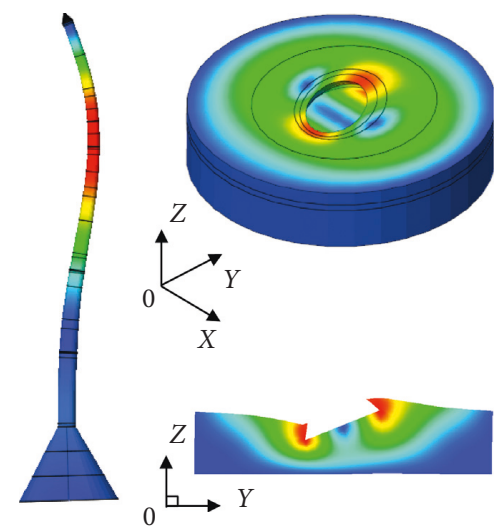

(c)

Figure 4: Across-wave directional bending modes from eigenvalue analysis. (a) Mode By1 (0.2840 Hz). (b) Mode By2 (1.5897 Hz). (c) Mode By3 $(2.4576 \mathrm{~Hz})$.

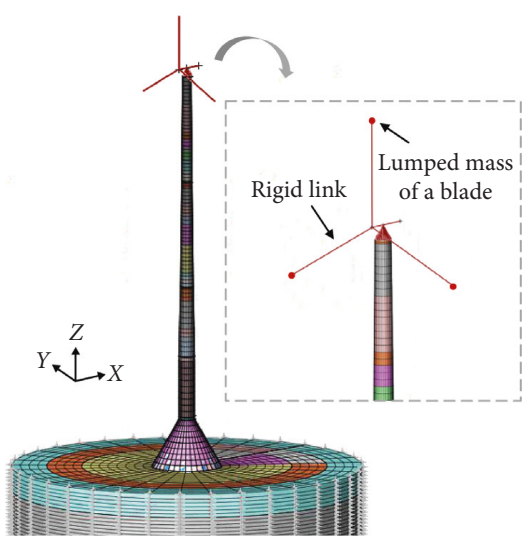

(a)
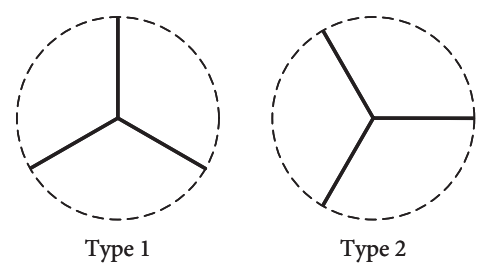

Type 2

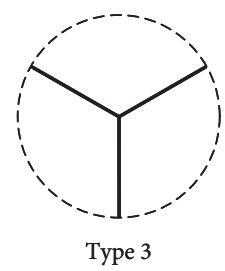

(b)
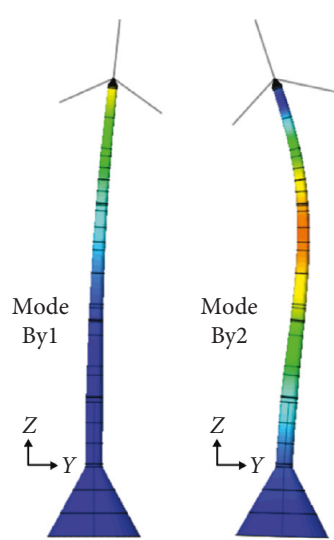

(c)

Figure 5: Blades-detailed FE model and its eigenvalue analysis for three orientation types of blades. (a) Modeling of blades. (b) Orientations of blades (c) Mode shapes of modes By1-3. 


\section{Waves and Damage Scenarios on GBF WTT}

\subsection{Analysis of Wave-Induced Dynamic Pressures on GBF WTT}

3.1.1. Wave Field Modeling. As schematized in Figure 6, the wave field has the following dimensions: $1500 \mathrm{~m}$ in length, $70 \mathrm{~m}$ in width, and $18 \mathrm{~m}$ in height. The incident wave propagated in the $X$ direction, and the caisson foundation was located at $70 \mathrm{~m}$ far from the wave generation source. The dimensions of the wave field were determined so that the influence of reflecting waves could be minimized. Regarding the boundary condition, the min-X plane was the plane of wave generation while the max-X plane was the outflow of the domain. The min- $Z$ plane was set to be a wall as the representation of the seabed. The remaining planes were defined as the symmetry condition, as shown in Figure 6. As listed in Table 4, four wave cases were selected to simulate the waveinduced dynamic pressure on the GBF WTT. The wave data were observed at $32^{\circ} \mathrm{N}-127^{\circ} \mathrm{E}$ near Jeju Island (Korea) in January 2017 [23]. The selected wave height ranges from $0.5 \mathrm{~m}$ to $4.6 \mathrm{~m}$ while the selected wave period ranges from $5.5 \mathrm{~s}$ to $6.5 \mathrm{~s}$. was used as an input for the wave field.

\subsubsection{Simulation of Wave-Induced Dynamic Pressures.} From the wave field analysis, wave pressures were simulated on the caisson foundation. Figure 7 shows the wave pressure calculated for Wave 2 at $t=0.9 \mathrm{~s}$ and $4.0 \mathrm{~s}$. Wave crest is located at behind of the caisson foundation when $t=0.9 \mathrm{~s}$ while crest of Wave 2 is located in front of the caisson foundation when $t=4.0 \mathrm{~s}$. In the direction of wave propagation, as indicated in Figure 7(a), Node 1 behind the caisson foundation had the largest pressure while Node 19 in front of the caisson foundation had the smallest pressure when $t=0.9 \mathrm{~s}$. Node $19 \mathrm{in}$ front of the caisson foundation had the largest pressure when $t=0.9 \mathrm{~s}$, while Node 1 behind the caisson foundation had the smallest pressure. The wave pressure at each node also changed with the depth. As shown in Figure 7(b), wave pressures at Node 1 and Node 19 increased linearly with the depth in both cases of $t=0.9 \mathrm{~s}$ and $4.0 \mathrm{~s}$; meanwhile, the pressure gap between them slightly decreased with the depth. Dynamic wave pressures at Node 1 were simulated for two different depths (e.g., $d=-2.2 \mathrm{~m}$ and $d=-11.2 \mathrm{~m}$ ), as shown in Figure 8 . Under the regular wave condition, the pressure fluctuation was decreased as the depth was increased.

\subsection{Analysis of Damage Scenarios on GBF WTT}

3.2.1. Selection of Damage Types. As previously described in Figure 1, the GBF WTT consists of three subsystems (i.e., tower, caisson, and foundation bed). In this study, typical three damage types of the subsystems are selected to examine their relative impacts on vibration characteristics of the GBF WTT.

Damage type 1 was bolt failure in the segmental tower. The tower was fabricated by several segments connected by bolted flanges, as previously described in Figures 1 and 3.
The failure of local bolts in the flange connection would cause severe reduction of flexural rigidity at the local zone; therefore, the damage should be monitored at its incipient stage. Otherwise, undetected extensive damage would result in global failure of the tower under extreme loading conditions.

Damage type 2 was the loss of infill aggregate in the caisson. The infill sand plays a primary role to maintain the stabilization of the GBF WTT under the sea environment, as shown in Figure 1(b). The loss of infill can occur by the leakage of infill through cracks and low quality of the construction. In gravity-type structure, loss of weight is one of the major damage types. The effect of crack on structural integrity is relatively smaller than those of weight loss due to the leakage of infill.

Damage type 3 was the scouring in the foundation bed. As shown in Figure 1(c), the foundation bed consists of the scour protection layer, gravel and filter layer, backfill layer, and natural ground. For example, wave-induced vortex would cause the local scour or erosion. In the field, the foundation bed of the gravity-based system is vulnerable to the local scour or erosion phenomena which would eventually result in the instability of the entire system. The scouring occurs with respect to current direction. The scouring starts behind the structure and expands in the current direction with increased width.

\subsubsection{Simulation of Bolt Damage in Tower Flange (Damage} Type 1). The tower has three main segments which are tightly connected by using four flanges (Figure 2(a)). The first flange has 140 bolts, while the second and third flanges have 108 and 100 bolts, respectively. The fourth flange is used to connect the hub with the tower. In the flange, a bolt failure is assumed as a totally loosened state. As shown in Figure 9, the bolt failure was simulated by splitting nodes corresponding to the bolt between upper and lower flange elements. It is noted that damaged bolts were placed at the along-wave $(x)$ direction. The severity was computed by the ratio of the number of loosened bolts in the flange. Three damage scenarios of bolt loosening were simulated as outlined in Table 5.

3.2.3. Infill Sand Loss in Caisson (Damage Type 2). The loss of infill sand would cause negative effects on the structural performance. In the simulation, it was assumed that the effect of crack is relatively small and focused on weight loss via reducing volume of infill sand without crack modeling. The saturation of infill sand due to refill of water into the caisson was not considered since the crack was not defined in this simulation. As shown in Figure 10, the loss of infill sand was simulated by removing elements of the lost region in the FE model. Three damage cases were inflicted as follows. The total volume of the infill sand was calculated as $3,115.5 \mathrm{~m}^{3}$. In the first case (DC1), the lost volume was inflicted as $69 \mathrm{~m}^{3}$ and the severity was estimated as $2 \%$. In the second case (DC2), the lost volume was $138 \mathrm{~m}^{3}$ and the severity was $4 \%$. In the third case (DC3), the lost volume was $207 \mathrm{~m}^{3}$ and the severity was $6 \%$. The severity was estimated 


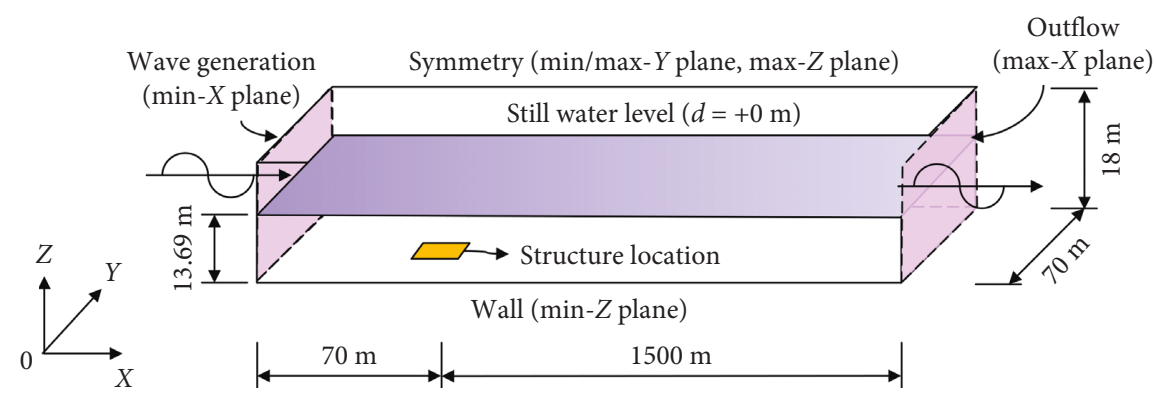

Figure 6: Numerical modeling of the wave field in Flow-3D.

TABLE 4: Wave properties for numerical modeling.

\begin{tabular}{lclcc}
\hline Cases & $\begin{array}{c}\text { Observation } \\
\text { time }\end{array}$ & Wave type & Wave height $(\mathrm{m})$ & $\begin{array}{c}\text { Wave } \\
\text { period (s) }\end{array}$ \\
\hline Wave 1 & 1st Jan. 2017 & Significant & 0.5 & 6 \\
Wave 2 & 3rd Jan. 2017 & Significant & 1.34 & 6.1 \\
Wave 3 & 5th Jan. 2017 & Maximum & 2.8 & 5.5 \\
Wave 4 & 9th Jan. 2017 & Maximum & 4.6 & 6.5 \\
\hline
\end{tabular}

as the ratio between the lost to the total volume of the infill sand in the concrete caisson. The damage was not oriented to any direction due the lost volume.

\subsubsection{Scouring in Foundation Bed (Damage Type 3). The} scouring in the foundation bed was simulated via removing elements of the scouring region in the FE model, as shown in Figure 11. Three damage cases were inflicted as follows. The total volume and the surface area of the foundation bed were calculated as $128,299 \mathrm{~m}^{3}$ and $6,232 \mathrm{~m}^{2}$, respectively. In the first case (DF1), damage was simulated with the severity of $0.4 \%$ by selecting the scouring depth of $0.4 \mathrm{~m}$ and the surface area of $120.2 \mathrm{~m}^{2}$. In the second case (DF2), damage was simulated with the severity of $1.7 \%$ by selecting the scouring depth of $6.3 \mathrm{~m}$ and the surface area of $354.2 \mathrm{~m}^{2}$. In the third case (DF3), damage was simulated with the severity of $4.4 \%$ by selecting the scouring depth of $6.3 \mathrm{~m}$ and the surface area of $885.1 \mathrm{~m}^{2}$. The severity was estimated as the ratio between the scouring over the total volume of the foundation bed. It is noted that the scouring damage was simulated back of the tower along the wave flow direction.

\section{Analysis of Vibration Characteristics of GBF WTT}

4.1. Wave-Induced Vibration Responses. Vibration monitoring in the GBF WTT is limited due to the restriction of sensor placement and excitation source. Since the caisson foundation is submerged under seawater, only the tower is accessible for vibration measurement. The wave-induced excitation on the rigid caisson produces complex vibration responses that represent both the flexible tower and the deformable foundation. In field practice, however, it is very hard to estimate the input wave load acting on the GBF WTT so that the available information is limited as the output vibration response (e.g., acceleration signal of the WTT).
The vibration measurement condition in real would be the operating status of the wind turbine blade. The operating status is resulting noises from unwanted vibration causes by wind, operated rotor, and blades. On the contrary, the vibration monitoring method has not been studied for various damage types. A few studies dealt with the monitoring of the tower part [24-26]. Therefore, the noisy condition was not considered to focus on the effect of three damage types on modal parameters.

Since a structural system is represented by stiffness, mass, and damping properties, its acceleration responses depend on the structural properties as defined:

$$
\ddot{u}_{t}=[\mathrm{M}]^{-1}\left(\{F\}-\dot{u}_{t}[\mathrm{C}]-u_{t}[\mathrm{~K}]\right) \text {, }
$$

where $u_{t}, \dot{u}_{t}$, and $\ddot{u}_{t}$ represent the displacement, velocity, and acceleration vectors, respectively; $[\mathrm{M}],[\mathrm{K}]$, and $[\mathrm{C}]$ represent the mass, stiffness, and damping matrices of the GBF WTT system, respectively; and $\{F\}$ is the vector of external wave forces. The acceleration response provides the information on the dynamic characteristics that may be feasible for structural integrity assessment.

To analyze the wave-induced vibration responses, the wave pressures simulated from the wave field (Figures 7 and 8) were applied to the FE model of the GBF WTT (Figure 2). The measuring period and the sampling rate were set as $330 \mathrm{sec}$ and $50 \mathrm{~Hz}$, respectively. It is noted that the $x, y$, and $z$ directions in the FE model indicate the along-wave, the across-wave, and the vertical directions. Figure 12 illustrates the three-directional acceleration signals of Sensor 7 computed under Wave 2 (as outlined in Table 2).

Acceleration responses were analyzed for the four waves. Table 6 outlines maximum values of acceleration signals obtained for the $x, y$, and $z$ directions. For Wave 2, the maximum acceleration values of Sensor 7 were computed as follows: (a) the along-wave direction had $0.076 \mathrm{~m} /$ $\mathrm{s}^{2}$ occurred at the first $5 \mathrm{sec}$, (b) the across-wave direction had only $0.021 \mathrm{~m} / \mathrm{s}^{2}$ within the first $10 \mathrm{~s}$, and (c) the vertical direction had $0.924 \mathrm{~m} / \mathrm{s}^{2}$ occurred instantly at the wave action. The vertical acceleration response was similar to the response induced by an impact excitation.

\subsection{Modal Parameter Estimation of GBF WTT}

4.2.1. Output-Only Modal Analysis Method. For the waveinduced random excitation, vibration responses are output- 

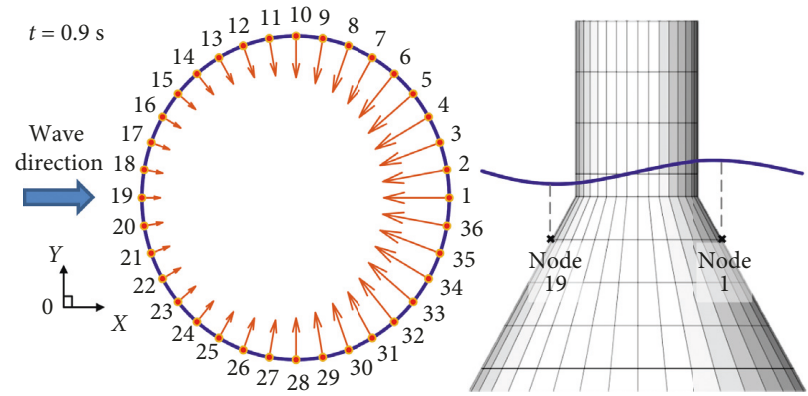
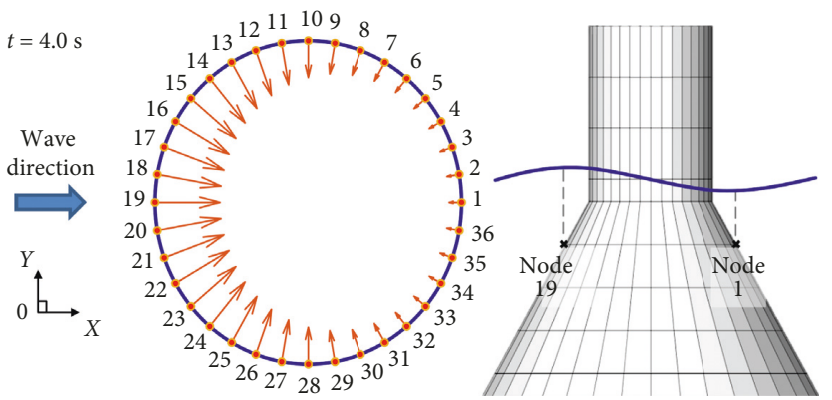

(a)
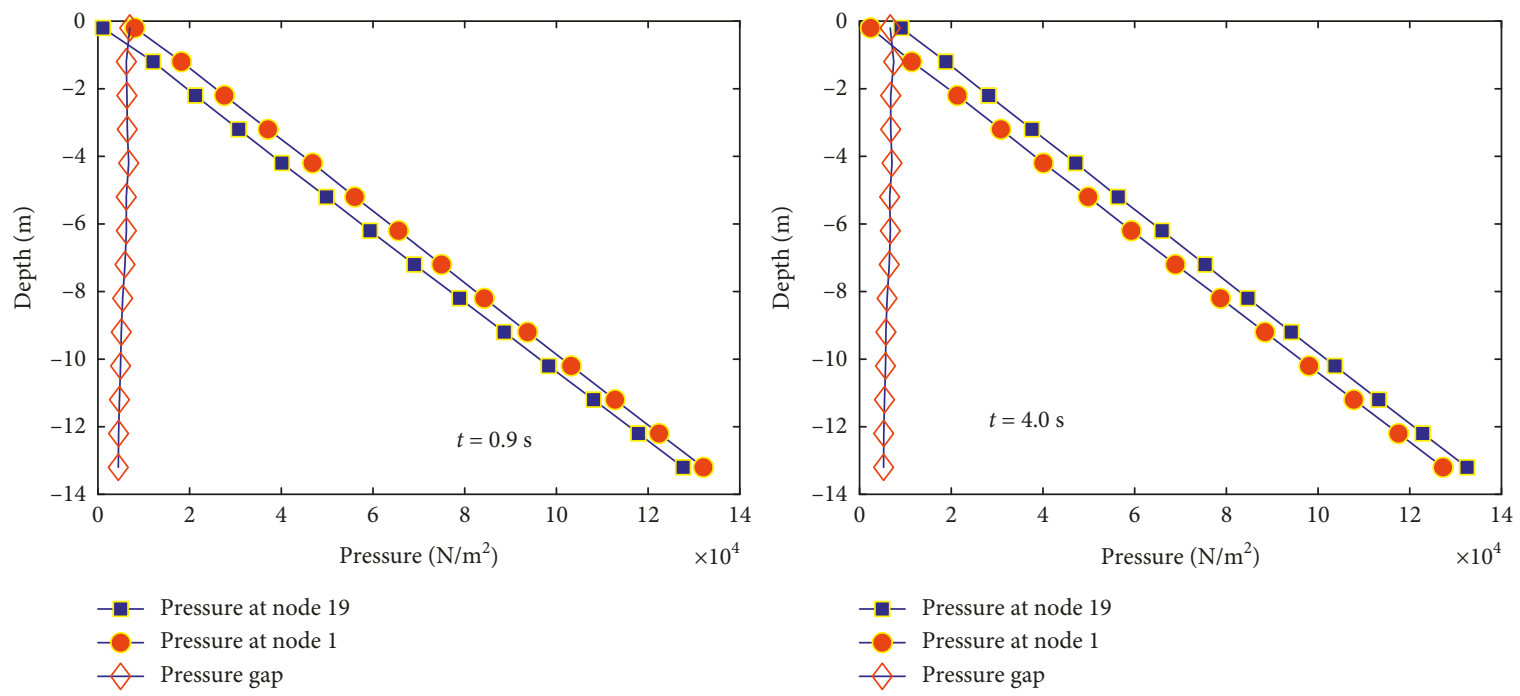

(b)

Figure 7: Wave pressure on the caisson foundation at $t=0.9 \mathrm{~s}$ and $4.0 \mathrm{~s}$ under Wave 2. (a) Wave pressure at depth $d=-2.2 \mathrm{~m}$. (b) Wave pressure vs depth.

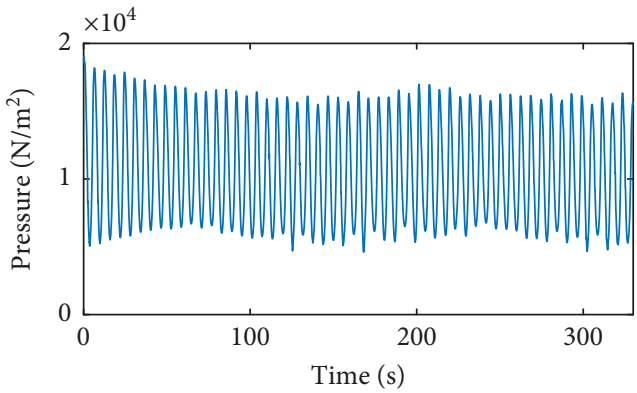

(a)

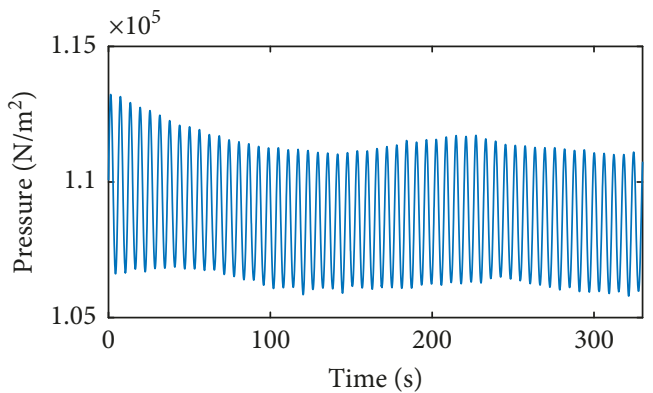

(b)

Figure 8: Wave pressure on the caisson foundation at Node 1 under Wave 2. (a) Depth $d=-2.2 \mathrm{~m}$. (b) Depth $d=-11.2 \mathrm{~m}$.

only (i.e., unknown input force) data. For the output-only vibration responses, time-domain and frequency-domain approaches are selected to extract modal parameters such as natural frequency, modal damping, and mode shape of the GBF WTT system.

As the time-domain method, we selected the stochastic subspace identification (SSI) method [13,27-29]. Firstly, cross-correlation matrices are calculated from measured time signals. Hankel matrix $[\mathbf{H}]$ is constructed from the obtained correlation matrices, and invertible weighting matrices $\mathbf{W}_{1}$ and $\mathbf{W}_{2}$ are multiplied to the Hankel matrix.
Then, this matrix is decomposed into the observability $\mathcal{O}_{n 1}$ and the system matrix $\mathrm{A}$ as

$$
\begin{aligned}
\mathbf{W}_{1} \mathbf{H} \mathbf{W}_{2} & =\left[\mathbf{U}_{1} \cdot \mathbf{U}_{2}\right]\left[\begin{array}{cc}
\sum_{1} & 0 \\
0 & 0
\end{array}\right]\left[\begin{array}{l}
\mathbf{V}_{1}^{\mathrm{T}} \\
\mathbf{V}_{2}^{\mathrm{T}}
\end{array}\right] \\
& \approx \mathbf{U}_{1} \sum_{1} \mathbf{V}_{1}^{\mathrm{T}} \Leftrightarrow \mathbf{W}_{1} \boldsymbol{O}_{n 1} \boldsymbol{O}_{n 2} \mathbf{W}_{2},
\end{aligned}
$$

where $\mathbf{U}, \mathbf{V}$, and $\sum_{1}$ are the unitary matrices and the singular value matrix, respectively. Next, the system matrix $\mathbf{A}$ is obtained from the observability matrix $\mathscr{O}_{n 1}$. The eigenvalues 


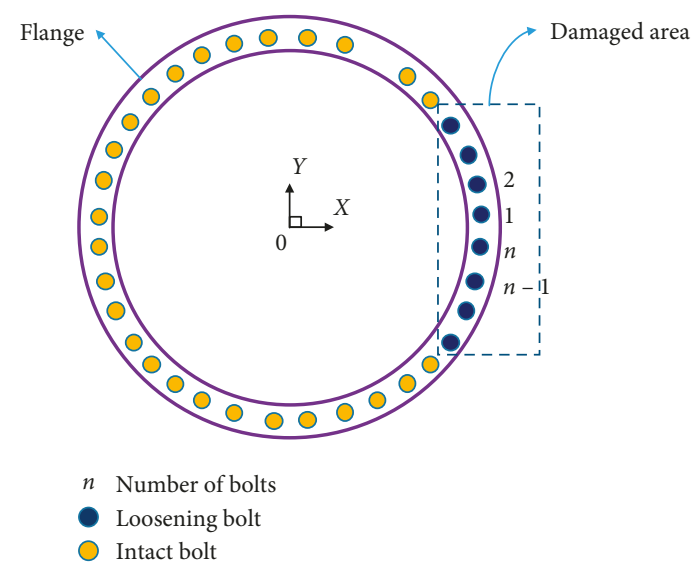

FIgURE 9: Simulation of damaged bolts in the tower flange.

TABle 5: Scenarios of bolt damage in the tower flange.

\begin{tabular}{lccccc}
\hline Case & \multicolumn{2}{c}{ Damage location } & \multicolumn{2}{c}{ Number of } & Bolts \\
& Member & Height $(\mathrm{m})$ & Total & Damage & rate (\%) \\
\hline DT1 & Flange 1 & 0 & 140 & 28 & 20 \\
DT2 & Flange 2 & 19.76 & 108 & 21 & 20 \\
DT3 & Flange 3 & 48.77 & 100 & 20 & 20 \\
\hline
\end{tabular}

$\mu$ and the eigenvectors $\psi$ of the system are computed by decomposing the system matrix $\mathbf{A}$ as

$$
\begin{aligned}
\mathbf{A} \Psi & =\boldsymbol{\Psi} \mathbf{M}\left(\mathbf{M}=\operatorname{diag}\left(\mu_{1}, \mu_{2}, \ldots, \mu_{N}\right) \in \mathbf{R}^{N \times N},\right. \\
\Psi & \left.=\left[\psi_{1}, \psi_{2}, \ldots, \psi_{N}\right] \in \mathbf{R}^{N \times N}\right) .
\end{aligned}
$$

Then a proper system order is decided via the stabilization chart.

We also selected the frequency-domain decomposition (FDD) method [29, 30]. Firstly, a power spectral density (PSD) matrix is calculated from a set of output responses acquired from $n$ sensors on a structure. Then the PSD matrix is decomposed by using the singular value decomposition (SVD) algorithm as follows:

$$
\mathbf{S}_{y y}(\omega)=\mathbf{U}(\omega)^{T} \sum(\omega) \mathbf{V}(\omega),
$$

where $\sum(\omega)$ is the diagonal matrix containing the singular values $\sigma_{i}(\omega)(i=1,2, \ldots, n)$ and $\mathbf{U}(\omega)$ and $\mathbf{V}(\omega)$ are unitary matrices. $\mathbf{U}(\omega)$ equals to $\mathbf{V}(\omega)$ since the PSD matrix $S_{y y}(\omega)$ is symmetric. Next, peak frequencies (i.e., natural frequency $\left.\omega_{n}\right)$ are identified in the first singular value $\sigma_{i}(\omega)$. The mode shapes are extracted from the column vectors of $\mathbf{U}(\omega)$ at the corresponding peak frequencies.

4.2.2. Modal Parameter Estimation. The wave-induced forced vibration analysis was performed, and the acceleration signals were extracted as shown in Figure 12. Regarding the acceleration signals, the sampling frequency was $f_{\mathrm{s}}=50 \mathrm{~Hz}$ and the measuring period was $T=330 \mathrm{~s}$; hence, the Nyquist frequency was $25 \mathrm{~Hz}$. In all vibration modes, the FDD method (resolution $0.012 \mathrm{~Hz}$ ) was first employed by using accelerations from Sensors 1 and 11 (as indicated in Figure 2(b)), and then the combined FDD and SSI methods (resolution
$0.006 \mathrm{~Hz}$ ) were utilized by using accelerations from all sensors to identify reliable modal parameters. Six bending modes (i.e., three along-wave bending modes and three across-wave bending modes) were identified at similar frequency with the eigenvalues (Table 3). Small differences were observed from natural frequencies, and it would come from different excitation conditions and discrete signal process.

Along-wave directional bending modes were identified as shown in Figure 13. The first peak at $0.1634 \mathrm{~Hz}$ resulted from the incident wave (i.e., Wave 2 with the significant wave period $\left.T_{\mathrm{s}}=6.1 \mathrm{~s}\right)$. Likewise, this phenomenon was also observed in other small aliasing peaks (i.e., nonstructural frequency responses). The first three along-wave bending modes were identified at $0.2933 \mathrm{~Hz}$ (Mode Bx1) $1.5606 \mathrm{~Hz}$ (Mode Bx2), and $2.4069 \mathrm{~Hz}$ (Mode Bx3). The corresponding mode shapes were extracted as shown in Figure 13(b). These extracted natural frequencies matched with those from the eigenvalue analysis, as listed in Table 7. It is observed that the difference between the eigenvalue and the wave-induced analyses was $0.26 \% \sim 3.51 \%$, with the largest gap in Mode Bx1.

Next, across-wave directional bending modes were identified as shown in Figure 14. The first three along-wave bending modes were identified at $0.2784 \mathrm{~Hz}$ (Mode By1), $1.5983 \mathrm{~Hz}$ (Mode By2), and $2.4632 \mathrm{~Hz}$ (Mode By3). The corresponding mode shapes were extracted as shown in Figure 14(b). These extracted natural frequencies matched with those from the eigenvalue analysis, as listed in Table 8. It is observed that the difference between the eigenvalue and the wave-induced analyses was $0.23 \% \sim 2.01 \%$, with the largest gap in Mode By1.

\section{Damage Assessment by Quantifying Modal Parameters}

5.1. Quantification of Modal Parameter Variation. Two measures were implemented to quantify changes in modal parameters induced by the three damage types. Firstly, the systematic variation of natural frequency was estimated between the intact and the damaged states. The relative variation of $i$ th natural frequencies before and after inflicting damage was calculated as

$$
\Delta F R_{i}=\frac{\left(f_{i}^{*}-f_{i}\right)}{f_{i}} \times 100,
$$

where $f_{i}$ and $f_{i}^{*}$ are the $i$ th natural frequencies obtained from the intact and damaged states, respectively. The negative value of $\Delta \mathrm{FR}_{i}$ indicates that the relative variation of the $i$ th natural frequency decreases due to the reduction of the system stiffness or the increase of the system mass of the GBF WTT. Otherwise, the positive value of $\Delta \mathrm{FR}_{i}$ indicates contrarily the increase of the system stiffness or the reduction of the system mass. Considering the simulated damage types on the GBF WTT (Figures 9-11), there would be two possible options: stiffness reduction or mass reduction. Therefore, any negative $\Delta \mathrm{FR}_{i}$ value would be caused by the stiffness reduction, and any positive $\Delta \mathrm{FR}_{i}$ value would be caused by the mass reduction in the GBF WTT. 


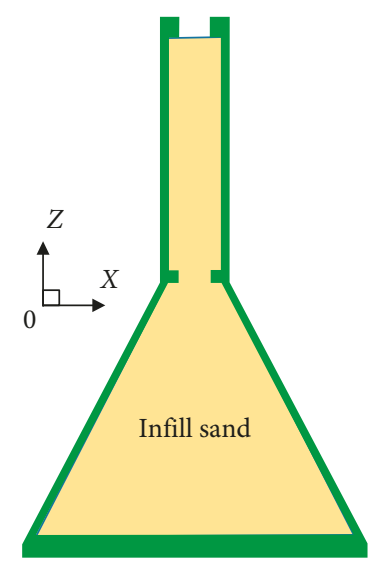

(a)

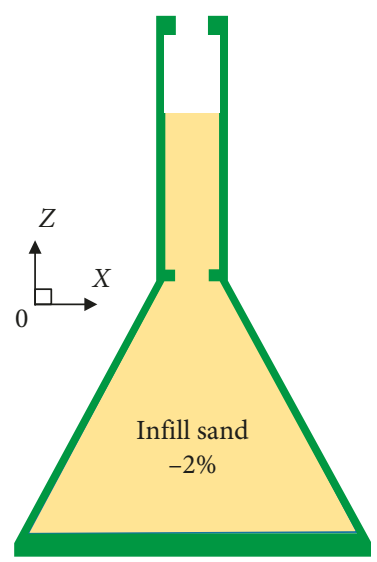

(b)

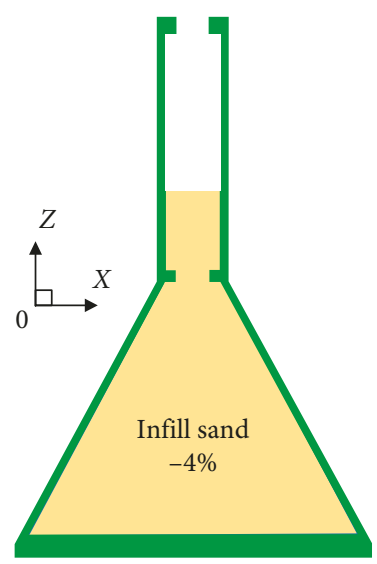

(c)

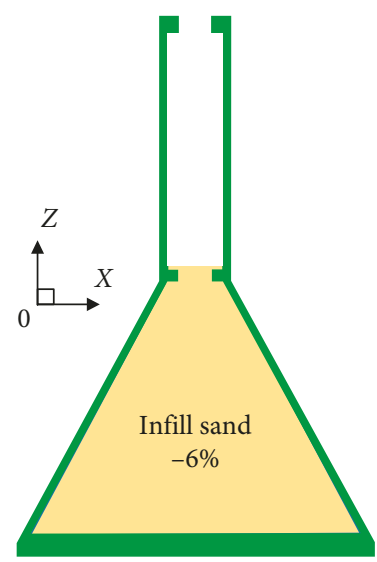

(d)

FIgure 10: Simulation of infill sand loss in the caisson. (a) Intact. (b) Case DC1. (c) Case DC2. (d) Case DC3.

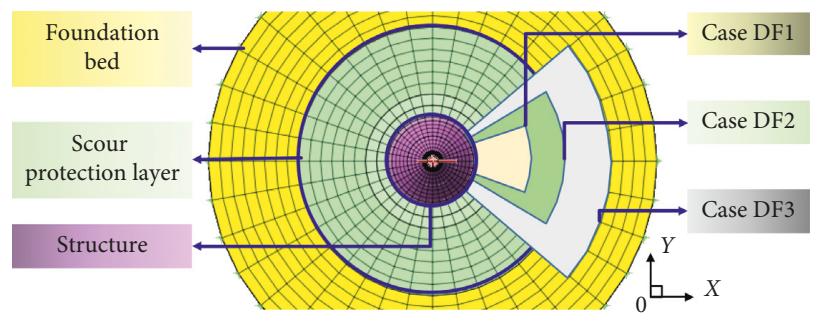

FIGURE 11: Simulation of scouring in the foundation bed.
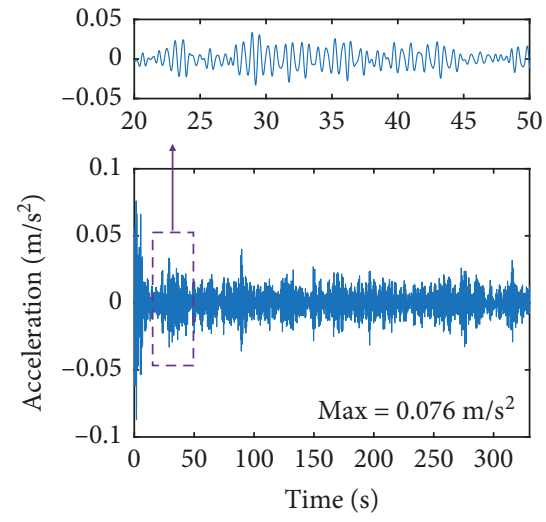

(a)
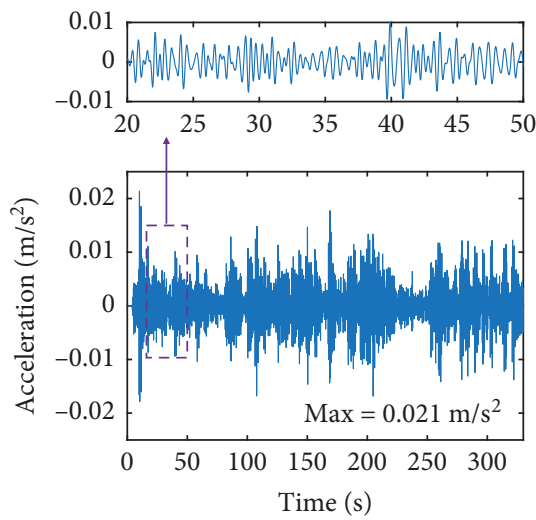

(b)

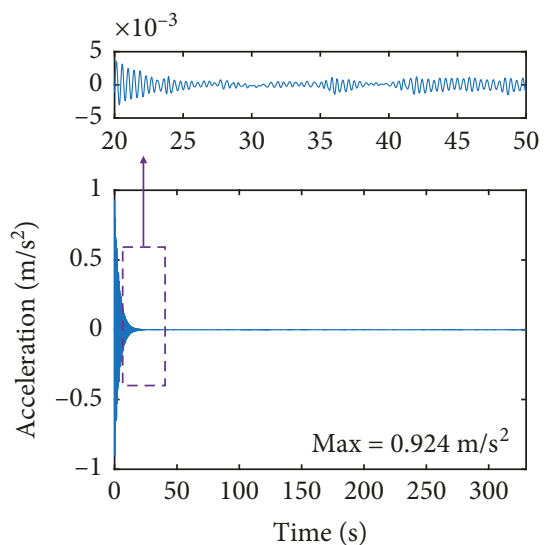

(c)

Figure 12: Three-directional acceleration signals of Sensor 7 under Wave 2. (a) Along-wave (x) direction. (b) Across-wave ( $y$ ) direction. (c) Vertical $(z)$ direction.

TABLE 6: Maximum accelerations from Sensor 7 under various waves.

\begin{tabular}{lccc}
\hline Cases & & Maximum value of acceleration $\left(\mathrm{m} / \mathrm{s}^{2}\right)$ & \\
& Along-wave $x$ direction & Across-wave $y$ direction & Vertical $z$ direction \\
\hline Wave 1 & 0.0152 & $7.00 \mathrm{E}-07$ & 0.9064 \\
Wave 2 & 0.0760 & 0.0210 & 0.9240 \\
Wave 3 & 0.6611 & 0.1980 & 0.9034 \\
Wave 4 & 0.2284 & 0.1501 & 1.0038 \\
\hline
\end{tabular}




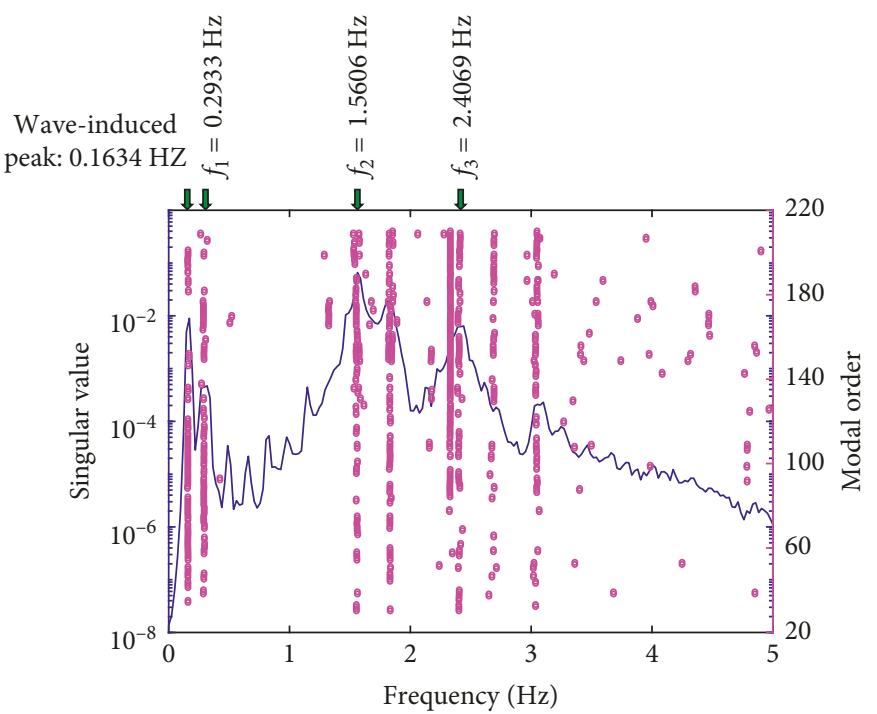

(a)

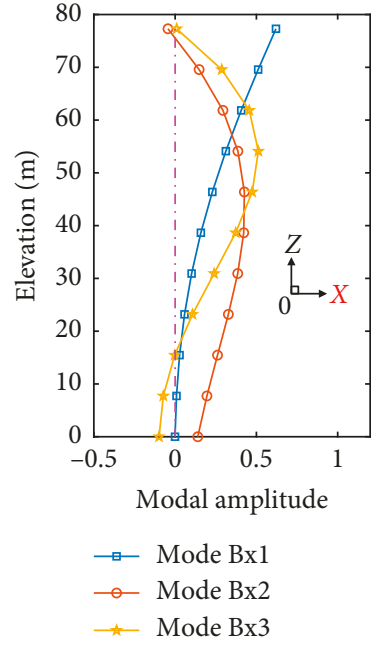

(b)

Figure 13: Modal parameter estimation for along-wave bending modes. (a) Singular value chart. (b) Mode shapes.

TABLE 7: Natural frequencies of along-wave bending modes.

\begin{tabular}{lccc}
\hline Analysis type & \multicolumn{2}{c}{ Along-wave mode } & Bx3 \\
& Bx1 & Bx2 & $2.4006 \mathrm{~Hz}$ \\
Eigenvalue & $0.2830 \mathrm{~Hz}$ & $1.5619 \mathrm{~Hz}$ & $2.4069 \mathrm{~Hz}$ \\
Wave induced & $0.2933 \mathrm{~Hz}$ & $1.5606 \mathrm{~Hz}$ & $0.26 \%$ \\
Difference & $3.51 \%$ & $0.08 \%$ & 0 \\
\hline
\end{tabular}

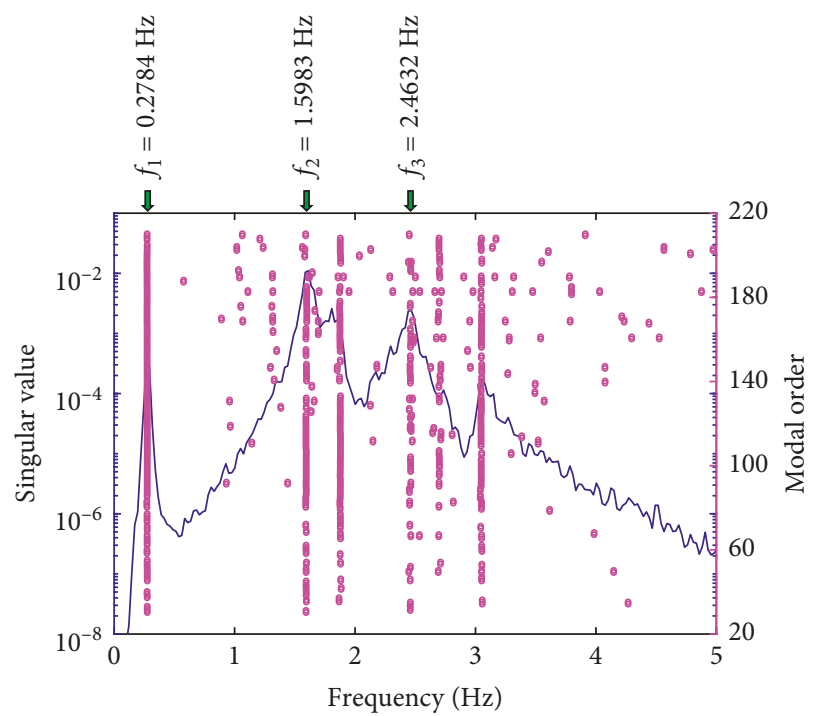

(a)

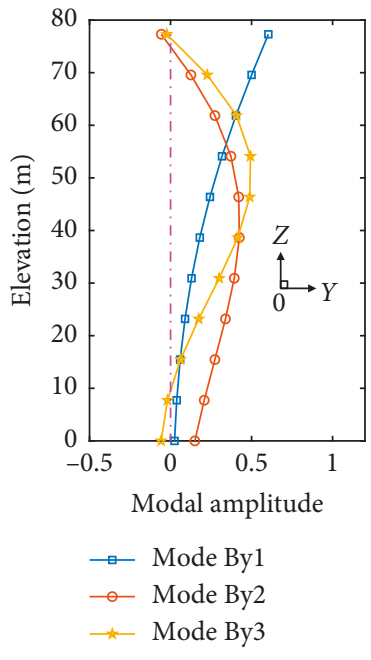

(b)

Figure 14: Modal parameter estimation for across-wave bending modes. (a) Singular value chart (b) Mode shapes.

TABLE 8: Natural frequencies of across-wave bending modes.

\begin{tabular}{lccc}
\hline Analysis type & \multicolumn{3}{c}{ Along-wave mode } \\
& By1 & By2 & $2.4576 \mathrm{~Hz}$ \\
\hline Eigenvalue & $0.2840 \mathrm{~Hz}$ & $1.5897 \mathrm{~Hz}$ & $2.4632 \mathrm{~Hz}$ \\
Wave induced & $0.2784 \mathrm{~Hz}$ & $1.5983 \mathrm{~Hz}$ & $0.23 \%$ \\
Difference & $2.01 \%$ & $0.54 \%$ & \\
\hline
\end{tabular}


Next, the variation of mode shape was estimated between the intact and three damage states. To quantify the level of linear correlation between two sets of mode shapes of the $i$ th mode, the modal assurance criterion was calculated as [31]

$$
\operatorname{MAC}\left(\Phi_{i}, \Phi_{i}^{*}\right)=\frac{\left[\Phi_{i}^{T} \Phi_{i}^{*}\right]^{2}}{\left[\Phi_{i}^{T} \Phi_{i}\right]\left[\Phi_{i}^{* T} \Phi_{i}^{*}\right]}
$$

where $\Phi_{i}$ and $\Phi_{i}^{*}$ are vectors of the $i$ th mode shapes obtained from the intact and the damaged states. The unity of MAC indicates that the two mode shapes are completely identical and no change is induced by damage. Otherwise, the MAC value less than the unity indicates that the two mode shapes have systematic difference due to the occurrence of damage. Usually, damage severity becomes relatively high as the MAC value becomes lower. Considering the complex behavior of the GBF WTT (which mainly includes the tower's flexible motion, the caisson's rigid motion, and the foundation's deformable motion), it is important to quantify the relative MAC values of the mode shapes with respect to the damage types.

\subsection{Variation of Modal Parameters Induced by Three Damage Types}

5.2.1. Damage Assessment Results: Damage Type 1. The variation of modal parameters of the GBF WTT was estimated for the bolt damage simulated in the tower flange (Figure 9 and Table 5). Firstly, relative changes in natural frequencies of the along-wave and across-wave bending modes were estimated as outlined in Tables 9 and 10. In the along-wave bending modes (Table 9), natural frequencies were reduced due to the inflicted damage, which was simulated by the bolt failure in the tower flange. The variation of natural frequency $(\Delta \mathrm{FR})$ ranged about $1.9 \% \sim 4.4 \%$ for Mode $\mathrm{Bx} 1$, which was relatively high as compared to other modes. It is observed that the $\Delta \mathrm{FR}$ was relatively high for the damage case DT2 (Figure 2(a)) due to the difference of damage location inflicted at the tower. In the across-wave bending modes (Table 10), there was no significant variation of natural frequencies due to the bolt damage (which was oriented to the along-wave sensitive position in the flange section). Note that the rate of bolt loss was set big enough to analyze the variation of modal parameters. For the investigation of detectability with respect to damage size, additional analyses with various damage scenarios are needed.

Next, mode shapes of the along-wave and across-wave bending modes were estimated for the bolt damage simulated in the tower, as shown in Figures 15 and 16, respectively. The variation of mode shapes was quantified by the modal assurance criterion (MAC), as shown in Figure 17. Regarding the along-wave mode shapes, there were only small changes in modal amplitudes of Modes Bx1 and Bx3 before and after damage. While the MAC value was nearly unity as shown in Figure 17(a), it varied highly in Mode Bx1 compared to other modes. Regarding the across-wave bending mode shapes, the mode shapes were not changed at all modes as shown in Figure 16. The MAC values were
TABLE 9: Natural frequencies of along-wave bending modes: damage type 1 .

\begin{tabular}{lcccccc}
\hline \multirow{2}{*}{ Case } & \multicolumn{2}{c}{ Mode Bx1 } & \multicolumn{2}{c}{ Mode Bx2 } & \multicolumn{2}{c}{ Mode Bx3 } \\
& $f(\mathrm{~Hz})$ & $\Delta \mathrm{FR}(\%)$ & $f(\mathrm{~Hz})$ & $\Delta \mathrm{FR}(\%)$ & $f(\mathrm{~Hz})$ & $\Delta \mathrm{FR}(\%)$ \\
\hline Intact & 0.2933 & - & 1.5606 & - & 2.4069 & - \\
DT1 & 0.2826 & -3.65 & 1.5552 & -0.35 & 2.3969 & -0.42 \\
DT2 & 0.2803 & -4.43 & 1.5576 & -0.19 & 2.4005 & -0.27 \\
DT3 & 0.2878 & -1.88 & 1.5471 & -0.87 & 2.3939 & -0.54 \\
\hline
\end{tabular}

TABle 10: Natural frequencies of across-wave bending modes: damage type 1 .

\begin{tabular}{lcccccc}
\hline \multirow{2}{*}{ Case } & \multicolumn{2}{c}{ Mode By1 } & \multicolumn{2}{c}{ Mode By2 } & \multicolumn{2}{c}{ Mode By3 } \\
& $f(\mathrm{~Hz})$ & $\Delta \mathrm{FR}(\%)$ & $f(\mathrm{~Hz})$ & $\Delta \mathrm{FR}(\%)$ & $f(\mathrm{~Hz})$ & $\Delta \mathrm{FR}(\%)$ \\
\hline Intact & 0.2784 & - & 1.5983 & - & 2.4632 & - \\
DT1 & 0.2786 & 0.07 & 1.5982 & -0.01 & 2.4589 & -0.17 \\
DT2 & 0.2787 & 0.11 & 1.5982 & -0.01 & 2.4560 & -0.29 \\
DT3 & 0.2784 & 0.00 & 1.5981 & -0.01 & 2.4598 & -0.14 \\
\hline
\end{tabular}

unities as shown in Figure 17(b). These results might be due to the orientation of the damaged region located at the along-wave direction. In the result of MAC, variations of mode shapes were rather small to compare with those of the natural frequency. It addressed that the only use of mode shapes would not be proper to identify the bolt-loss damage.

5.2.2. Damage Assessment Results: Damage Type 2. The variation of modal parameters of the GBF WTT was estimated for the loss of infill sand simulated in the concrete caisson (Figure 10). Relative changes in natural frequencies of the along-wave and across-wave bending modes were estimated as outlined in Tables 11 and 12. Overall, natural frequencies of those modes were increased due to the inflicted damage, which was simulated by infill sand loss in the caisson. The variation of natural frequency $(\Delta \mathrm{FR})$ ranged about $1.9 \% \sim 3.7 \%$ for Mode Bx2 and $2.0 \% \sim 3.5 \%$ for Mode By2, which were relatively high as compared to other modes. Damage DC1 (i.e., 2\% loss of infill sand) had relatively high variation of natural frequency as compared to Damage DC2 (i.e., $4 \%$ loss of infill sand) and Damage DC3 (i.e., 6\% loss of infill sand). It is noted that the infill sand loss caused the relative increase of flexural rigidity with respect to the position of the loss so that it contributed relatively to natural frequencies of the bending modes.

There were very small changes in mode shapes of the tower when the loss of infill sand was inflicted to the concrete caisson. It is noted that the tower was assumed to be measurable subsystem, while the caisson and foundation submerged. As shown in Figure 18, all MAC values were close to unities, which indicated insignificant change in mode shapes due to the damage. The MAC value slightly decreased up to 0.997 as the mode order increased both in along-wave and across-wave modes. Note that the variation of the modal parameter would be smaller when the refill of seawater through the crack is considered. In the result of MAC, variations of mode shapes were rather small to compare with those of the natural frequency. It addressed 


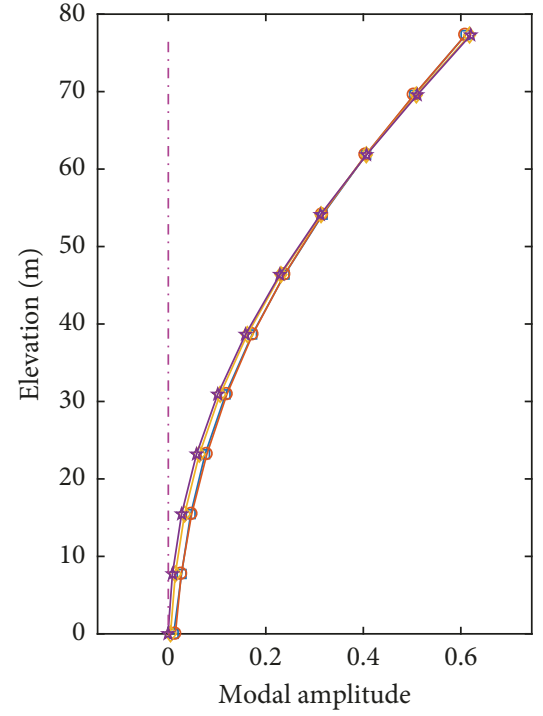

$\begin{array}{ll}\square \text { Intact } & \succ \text { Case DT2 } \\ - \text { Case DT1 } & \rightarrow \text { Case DT3 }\end{array}$

(a)

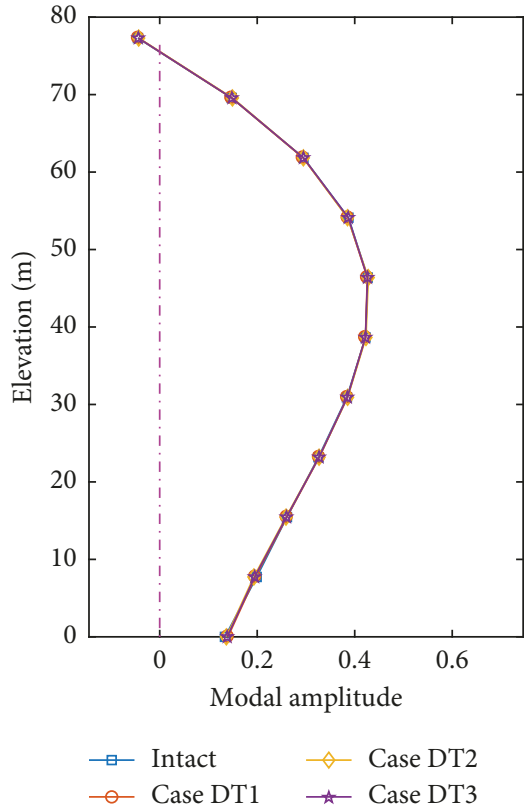

(b)

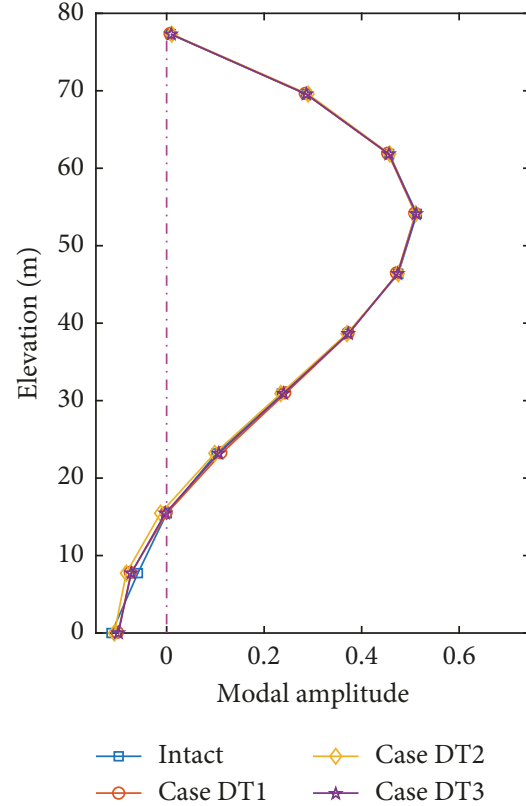

(c)

Figure 15: Along-wave bending mode shapes: damage type 1. (a) Mode Bx1. (b) Mode Bx2. (c) Mode Bx3.

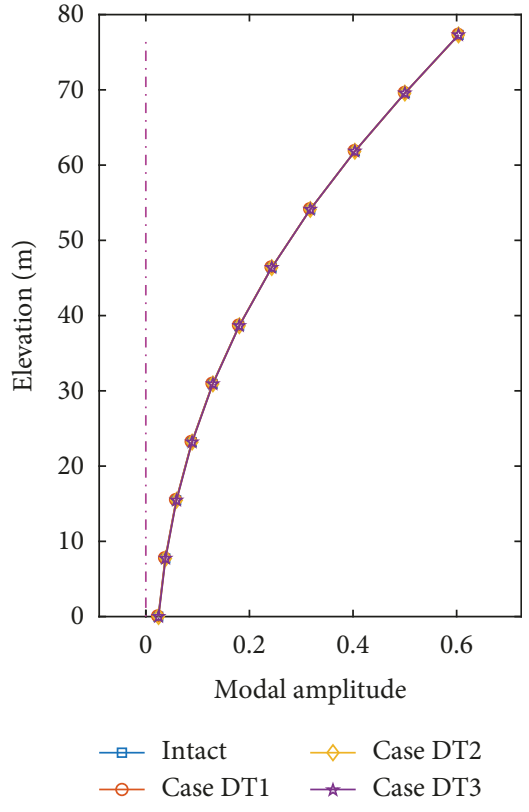

(a)

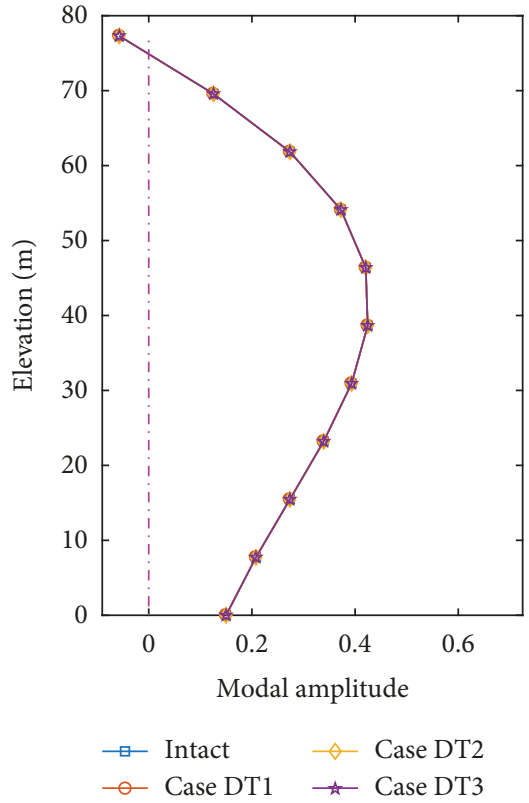

(b)

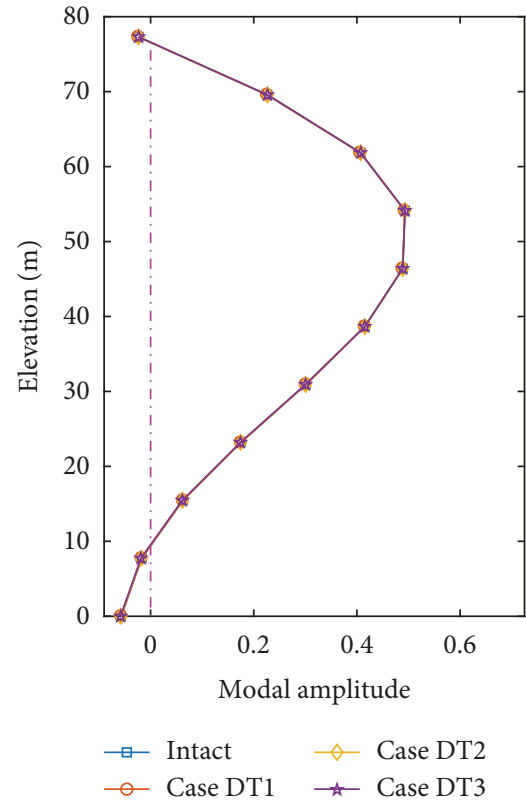

(c)

Figure 16: Across-wave bending mode shapes: damage type 1. (a) Mode By1. (b) Mode By2. (c) Mode By3.

that the only use of mode shapes would not be proper to identify the weight-loss damage.

5.2.3. Damage Assessment Results: Damage Type 3. The variation of modal parameters of the GBF WTT was estimated for the scouring simulated in the foundation bed (Figure 11). Relative changes in natural frequencies of the along-wave and across-wave bending modes were estimated as outlined in Tables 13 and 14. In the along-wave bending modes, natural frequencies were mostly decreased due to the inflicted damage, which indicates the stiffness reduction in the GBF WTT. The variation of natural frequency $(\Delta \mathrm{FR})$ ranged about $0.2 \% \sim 1.7 \%$ for Mode $\mathrm{Bx} 1$ and $0.8 \% \sim 2.4 \%$ for Mode Bx2. However, natural frequencies of the across-wave bending modes were not changed with a clear trend. It is 


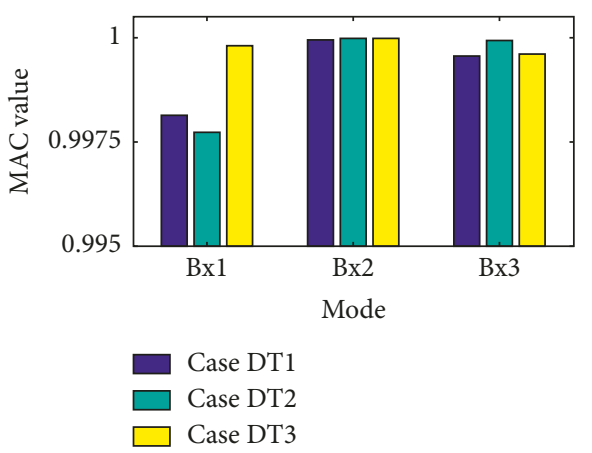

(a)

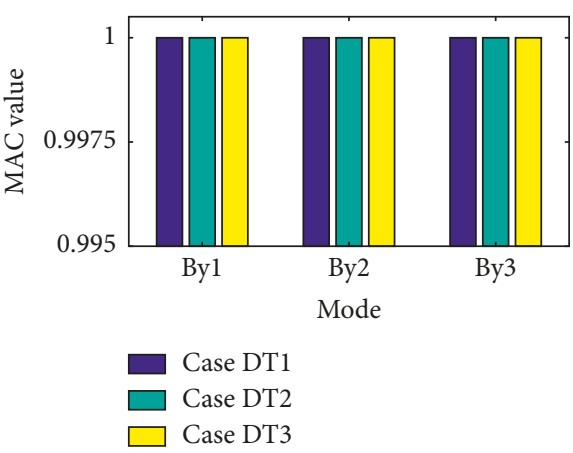

(b)

FIGURE 17: Modal assurance criterion (MAC) of mode shapes: damage type 1. (a) Along-wave modes. (b) Across-wave modes.

TABLE 11: Natural frequencies of along-wave bending modes: damage type 2 .

\begin{tabular}{|c|c|c|c|c|c|c|}
\hline \multirow{2}{*}{ Case } & \multicolumn{2}{|c|}{ Mode Bx1 } & \multicolumn{2}{|c|}{ Mode Bx2 } & \multicolumn{2}{|c|}{ Mode Bx3 } \\
\hline & $f(\mathrm{~Hz})$ & $\Delta f(\%)$ & $f(\mathrm{~Hz})$ & $\Delta f(\%)$ & $f(\mathrm{~Hz})$ & $\Delta f(\%)$ \\
\hline Intact & 0.2933 & - & 1.5606 & - & 2.4069 & - \\
\hline DC1 & 0.2935 & 0.07 & 1.5899 & 1.88 & 2.4270 & 0.84 \\
\hline DC2 & 0.2933 & 0.00 & 1.6098 & 3.15 & 2.4386 & 1.32 \\
\hline DC3 & 0.2934 & 0.03 & 1.6186 & 3.72 & 2.4480 & 1.71 \\
\hline
\end{tabular}

TABLE 12: Natural frequencies of across-wave bending modes: damage type 2.

\begin{tabular}{|c|c|c|c|c|c|c|}
\hline \multirow{2}{*}{ Case } & \multicolumn{2}{|c|}{ Mode By1 } & \multicolumn{2}{|c|}{ Mode By2 } & \multicolumn{2}{|c|}{ Mode By3 } \\
\hline & $f(\mathrm{~Hz})$ & $\Delta f(\%)$ & $f(\mathrm{~Hz})$ & $\Delta f(\%)$ & $f(\mathrm{~Hz})$ & $\Delta f(\%)$ \\
\hline Intact & 0.2784 & - & 1.5983 & - & 2.4632 & - \\
\hline $\mathrm{DC} 1$ & 0.2786 & 0.07 & 1.6305 & 2.01 & 2.4721 & 0.36 \\
\hline DC2 & 0.2787 & 0.11 & 1.6452 & 2.93 & 2.4850 & 0.89 \\
\hline DC3 & 0.2787 & 0.11 & 1.6535 & 3.45 & 2.5002 & 1.50 \\
\hline
\end{tabular}

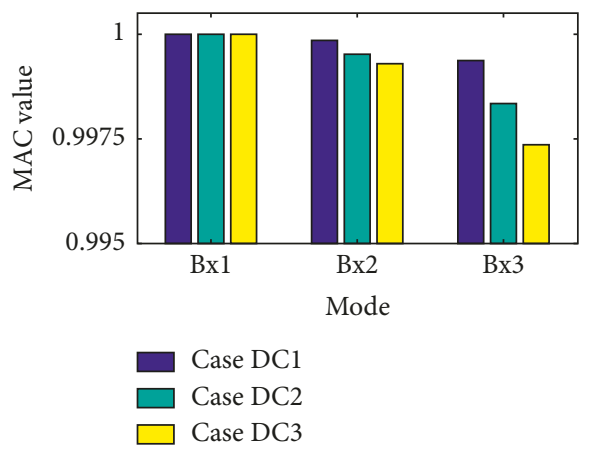

(a)

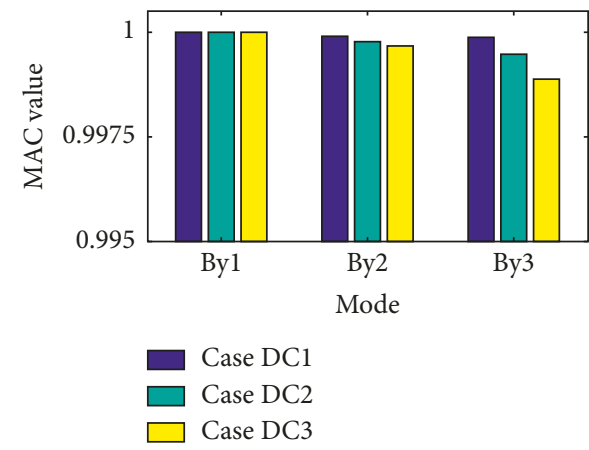

(b)

FIGURE 18: Modal assurance criterion (MAC) of mode shapes: damage type 2. (a) Along-wave modes. (b) Across-wave modes.

assumed that the position of the simulated scour had little impact on those modes.

There were very small changes in mode shapes of the tower when the scouring was inflicted to the foundation bed. It is reminded that the tower was the only measurable subsystem. As shown in Figure 19, there was no clear trend in MAC values. All MAC values were close to unities, which indicated insignificant change in mode shapes due to the damage. The MAC slightly decreased up to 0.9994 as the mode order increased; however, the value would not be physically measurable in the field. 
TABLE 13: Natural frequencies of along-wave bending modes: damage type 3.

\begin{tabular}{lcccccc}
\hline Case & \multicolumn{2}{c}{ Mode Bx1 } & \multicolumn{2}{c}{ Mode Bx2 } & \multicolumn{2}{c}{ Mode Bx3 } \\
& $f(\mathrm{~Hz})$ & $\Delta f(\%)$ & $f(\mathrm{~Hz})$ & $\Delta f(\%)$ & $f(\mathrm{~Hz})$ & $\Delta f(\%)$ \\
\hline Intact & 0.2933 & - & 1.5606 & - & 2.4069 & - \\
DF1 & 0.2926 & -0.24 & 1.5483 & -0.79 & 2.4052 & -0.07 \\
DF2 & 0.2893 & -1.36 & 1.5369 & -1.52 & 2.4358 & 1.20 \\
DF3 & 0.2882 & -1.74 & 1.5228 & -2.42 & 2.4180 & 0.46 \\
\hline
\end{tabular}

TABLE 14: Natural frequencies of across-wave bending modes: damage type 3.

\begin{tabular}{lcccccc}
\hline \multirow{2}{*}{ Case } & \multicolumn{2}{c}{ Mode By1 } & \multicolumn{2}{c}{ Mode By2 } & \multicolumn{2}{c}{ Mode By3 } \\
& $f(\mathrm{~Hz})$ & $\Delta f(\%)$ & $f(\mathrm{~Hz})$ & $\Delta f(\%)$ & $f(\mathrm{~Hz})$ & $\Delta f(\%)$ \\
\hline Intact & 0.2784 & - & 1.5983 & - & 2.4632 & - \\
DF1 & 0.2785 & 0.04 & 1.5958 & -0.16 & 2.4448 & -0.75 \\
DF2 & 0.2790 & 0.22 & 1.5980 & -0.02 & 2.4799 & 0.68 \\
DF3 & 0.2787 & 0.11 & 1.5884 & -0.62 & 2.4774 & 0.58 \\
\hline
\end{tabular}

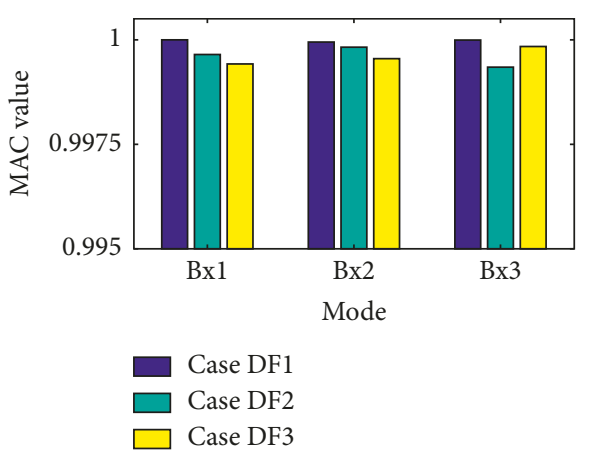

(a)

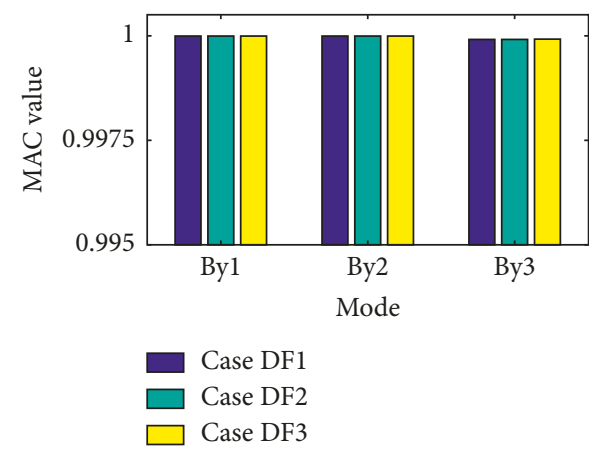

(b)

Figure 19: Modal assurance criterion (MAC) of mode shapes: damage type 3. (a) Along-wave modes. (b) Across-wave modes.

5.3. Wave-Induced Effect on Damage-Induced Modal Parameter Variation. The effect of various wave conditions (e.g., wave height and wave period) on modal parameters of the GBF WTT was estimated by the two measures, $\triangle \mathrm{FR}_{i}$ and MAC. Firstly, natural frequencies and mode shapes were analyzed for the four different wave conditions (i.e., Waves 1-4), as described in Table 4. Dynamic wave pressures corresponding to the four waves were simulated from the wave field analysis, as outlined in Table 7. Then three-directional acceleration response signals of the GBF WTT were analyzed for the four waves, as shown in Figure 12. From the wave-induced acceleration signals, natural frequencies and mode shapes were identified from the combined use of the SSI and FDD methods.

Next, the relative variation of natural frequencies induced by the various Waves 1-4 was estimated for the alongwave and across-wave modes, as shown in Figure 20. To estimate the relative variation, the natural frequency of the eigenvalue analysis (Table 2) was utilized as the reference. In the along-wave bending modes, the variation of natural frequency $(\triangle \mathrm{FR})$ ranged about $0.03 \% \sim 2.92 \%$ for Mode $\mathrm{Bx} 1$, $0.06 \% \sim 0.56 \%$ for Mode Bx2, and $0.06 \% \sim 0.65 \%$ for Mode $\mathrm{Bx} 3$. In the across-wave bending modes, the variation of natural frequency $(\triangle \mathrm{FR})$ ranged about $0.14 \% \sim 1.97 \%$ for Mode By1, 0.05\% 0.86\% for Mode By2, and 0.003\% 0.72\% for Mode By3.

Finally, the variation of mode shapes induced by the various Waves 1-4 was quantified by the modal assurance criterion (MAC), as shown in Figure 21. The MAC values of the along-wave and across-wave bending modes were estimated by comparing with the reference mode shapes from the eigenvalue analysis. For the along-wave mode shapes, there were small changes in modal amplitudes of Modes Bx1 under the various wave conditions (e.g., especially Wave 2). All other MAC values were nearly unities as shown in Figure 21(a). For the across-wave mode shapes, the mode shapes were not changed at all modes by indicating the MAC values close to unities, as shown in Figure 21(b). It is observed that the mode shapes of Mode Bx1 and Mode Byl were likely to change with the variation of wave conditions. So it is noted that the wave action had relatively high influence on the modal parameters when the wave period (i.e., the inverse of wave frequency) occurred near the natural frequency of the GBF WTT. Furthermore, it is recognized that the change in modal parameters induced by the three damage types could be hidden from the variation of waves in the field. 


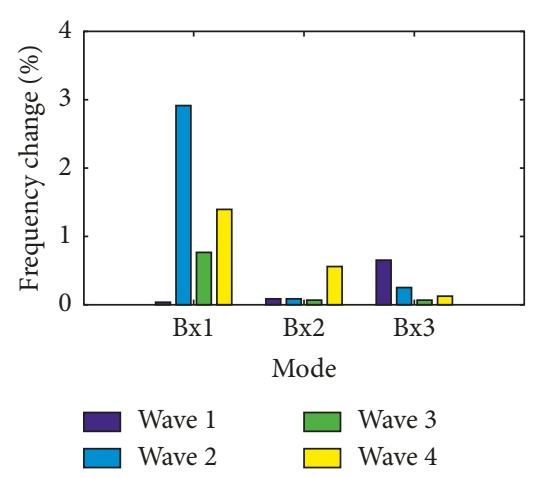

(a)

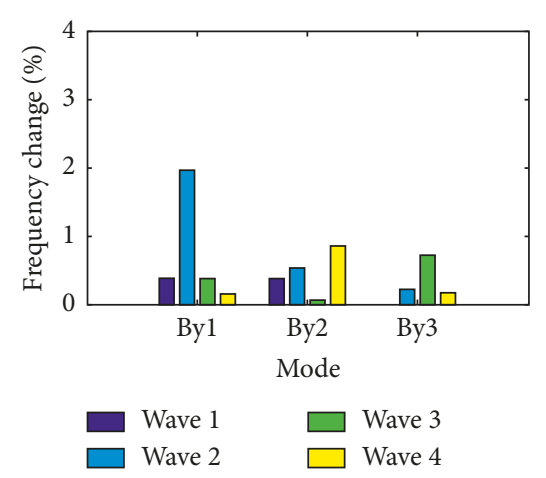

(b)

Figure 20: Variation of natural frequencies of Waves 1-4 relative to eigenvalue analysis. (a) Along-wave bending mode. (b) Across-wave bending mode.

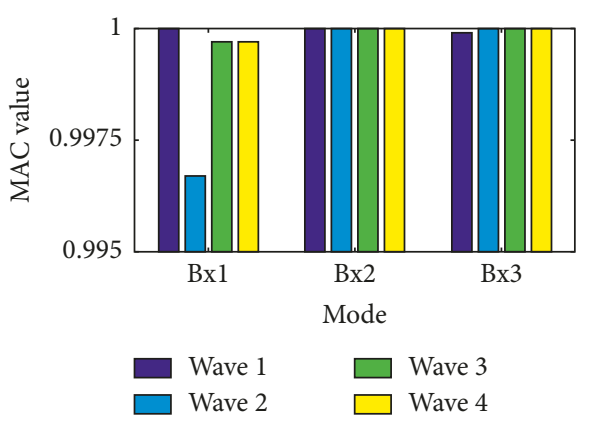

(a)

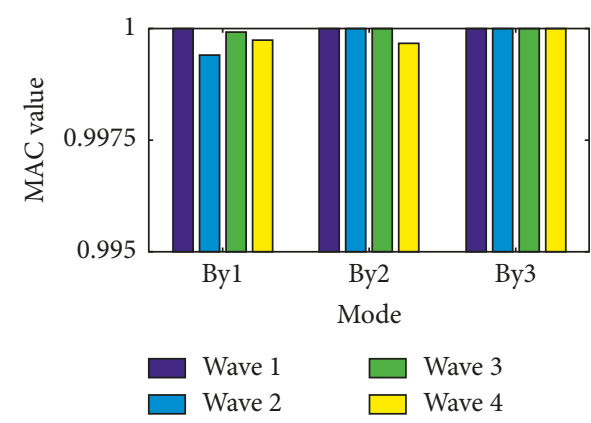

(b)

Figure 21: MAC values of mode shapes of Waves 1-4 relative to eigenvalue analysis. (a) Along-wave bending mode. (b) Across-wave bending mode.

\section{Conclusion}

The feasibility of vibration-based damage assessment was numerically investigated for a wind turbine tower (WTT) with gravity-based foundation (GBF) under various waves. Firstly, a finite element (FE) model of GBF WTT was generated. Eigenvalue analysis was performed, and six vibration modes of along-wave and across-wave directions were observed. Secondly, wave-induced dynamic pressures were analyzed for four waves selected from wave records of the target site. Three damage types which include bolt failure in tower flange, infill sand loss in concrete caisson, and scouring in foundation bed were also designed to simulate main components of the target GBF WTT. Modal parameters were extracted for the wave scenarios and the damage scenarios by a combined use of timedomain and frequency-domain modal identification methods. Finally, damage-induced effects were quantified from investigation of relative changes in natural frequencies and mode shapes. Also, the effect of various wave actions on the damageinduced variation of modal parameters was assessed by estimation of wave-induced variation of modal parameters.

From the numerical investigation, the following concluding remarks can be made:

(1) The observed modes represented complex behaviors of the flexible tower, rigid caisson, and deformable foundation. This addressed that vibration responses measured from the tower could be utilized in structural assessment relative to not only the tower but also caisson and foundation.

(2) The selected damage types had relatively different effects on the modal parameters of the GBF WTT. The damages which include bolt failure of tower flange and scouring of foundation resulted in decrease of most natural frequencies, while infill loss of the caisson resulted in increase of the natural frequencies. Also, mode shapes had relatively small variation with respect to the damages so that a single use of mode shapes would not be proper in structural assessment of the GBF WTT.

(3) The wave action had relatively high influence on the modal parameters when the wave period (i.e., the inverse of wave frequency) occurred near the natural frequency of the GBF WTT. Also, it is concluded that the change in modal parameters induced by the three damage types could be hidden from the variation of waves.

\section{Data Availability}

The data for numerical modeling of this study are included within the article. The other data are available from the corresponding author upon request. 


\section{Conflicts of Interest}

The authors declare that they have no conflicts of interest.

\section{Acknowledgments}

This work was supported by the Basic Science Research Program through the National Research Foundation of Korea (NRF) funded by the Ministry of Education, Science, and Technology (NRF2016R1A2B4015087).

\section{References}

[1] 4Coffshore, https://www.4coffshore.com/windfarms/gravitybased-support-structures-aid8.html, 2018.

[2] M. Damgaard, "Dynamic properties of offshore wind turbine foundations," Ph.D. thesis, Aalborg University, Aalborg, Denmark, 2014.

[3] S. Wang, Y. Huang, L. Li, C. Liu, and D. Zhang, "Dynamic analysis of wind turbines including nacelle-tower-foundation interaction for condition of incomplete structural parameters," Advances in Mechanical Engineering, vol. 9, no. 3, pp. 1-17, 2017.

[4] T. U. Petersen, B. Mutlu Sumer, J. Fredsøe, T. C. Raaijmakers, and J.-J. Schouten, "Edge scour at scour protections around piles in the marine environment-laboratory and field investigation," Coastal Engineering, vol. 106, pp. 42-72, 2015.

[5] S.-Y. Lee and J.-T. Kim, "Effects of foundation damage and water-level change on vibration modal parameters of gravitytype caisson structure," Science China Technological Sciences, vol. 58, no. 2, pp. 316-329, 2015.

[6] C. U. Nguyen, T. C. Huynh, N. L. Dang, and J. T. Kim, "Vibration-based damage alarming criteria for wind turbine towers," Structural Monitoring and Maintenance, vol. 4, no. 3, pp. 221-236, 2017.

[7] W. R. Wickramasinghe, D. P. Thambiratnam, T. H. T. Chan, and T. Nguyen, "Vibration characteristics and damage detection in a suspension bridge," Journal of Sound and Vibration, vol. 375, pp. 254-274, 2016.

[8] C. U. Nguyen, T. C. Huynh, and J. T. Kim, "Vibration-based damage detection in wind turbine towers using artificial neural networks," Structural Monitoring and Maintenance, vol. 5, no. 4, pp. 507-519, 2018.

[9] A. Banerjee, T. Chakraborty, and V. Matsagar, "Stochastic dynamic analysis of an offshore wind turbine considering frequency-dependent soil-structure interaction parameters," International Journal of Structural Stability and Dynamics, vol. 18, no. 6, article 1850086, 2018.

[10] M. D. Esteban, B. Couñago, J. S. López-Gutiérrez, V. Negro, and F. Vellisco, "Gravity based support structures for offshore wind turbine generators: review of the installation process," Ocean Engineering, vol. 110, pp. 281-291, 2015.

[11] R. D. Risi, S. Bhattacharya, and K. Goda, "Seismic performance assessment of monopile-supported offshore wind turbines using unscaled natural earthquake records," Soil Dynamic and Earthquake Engineering, vol. 109, pp. 154-172, 2018.

[12] H. Smaling, "Hydrodynamic loading on the shaft of a gravity based offshore wind turbine," Final Report Master Thesis, TU Delft, Delft, Netherlands, 2014.

[13] S.-Y. Lee, T.-C. Huynh, and J.-T. Kim, "A practical scheme of vibration monitoring and modal analysis for caisson breakwater," Coastal Engineering, vol. 137, pp. 103-119, 2018.
[14] D.-D. Ho, J.-T. Kim, N. Stubbs, and W.-S. Park, "Prestressforce estimation in PSC girder using modal parameters and system identification," Advances in Structural Engineering, vol. 15, no. 6, pp. 997-1012, 2012.

[15] H. Kim, S. Baek, E. Park, and H. J. Chang, "Optimal green energy management in Jeju, South Korea - on-grid and off-grid electrification," Renewable Energy, vol. 69, pp. 123-133, 2014.

[16] T.-C. Nguyen, T.-C. Huynh, and J.-T. Kim, "Numerical evaluation for vibration-based damage detection in wind turbine tower structure," Wind and Structures, vol. 21, no. 6, pp. 657-675, 2015.

[17] Daewoo E and C, Offshore Wind Concrete Gravity Based Substructure-Design and Construction Guidelines, Daewoo Institute of Construction Technology, Suwon City, South Korea, 2017.

[18] I. R. T. Alonso, "Gravity base foundations for offshore wind farms: marine operations and installation processes," Master Dissertation, University of Cantabria, Santander, Spain, 2013.

[19] P. Menge and N. Gunst, "Gravity base foundation for the wind turbines on the Thornton Bank-Belgium," in Proceedings of the 15th Innovatieforum Geotechniek, Antwerpen, Belgium, 2008.

[20] K. Peire, H. Nonneman, and E. Bosschem, "Gravity base foundations for the Thornton Bank offshore wind farm," in Proceedings of the CEDA, Antwerp, Belgium, January 2008.

[21] S.-Y. Lee, K.-D. Nguyen, T.-C. Huynh, J.-T. Kim, J.-H. Yi, and S.-H. Han, "Vibration-based damage monitoring of harbor caisson structure with damaged foundation-structure interface," Smart Structures and Systems, vol. 10, no. 6, pp. 517-546, 2012.

[22] D. D. Barkan, Dynamics of Bases and Foundations, McGrawHill Book Co., New York, NY, USA, 1962.

[23] Korean Hydrographic and Oceanographic Agency, Ocean Observation Newsletter-3rd Quarter 2017, National Oceanographic Research Institute, Incheon, South Korea, 2017.

[24] M. He, X. Bai, R. Ma, and D. Huang, "Structural monitoring of an onshore wind turbine foundation using strain sensors," Structure and Infrastructure engineering, vol. 15, no. 3, pp. 314-333, 2019.

[25] J. Lian, O. Cai, X. Dong, Q. Jiang, and Y. Zhao, "Health monitoring and safety evaluation of the offshore wind turbine structure: a review and discussion of future development," Sustainability, vol. 11, no. 2, p. 494, 2019.

[26] M. Perry, J. McAlorum, G. Fusiek, P. Niewczas, I. McKeeman, and T. Rubert, "Crack monitoring of operational wind turbine foundations," Sensors, vol. 17, no. 8, p. 1925, 2017.

[27] R. Brinker and P. Andersen, "Understanding stochastic subspace identification," in Proceedings of the 24th International Modal analysis Conference, St. Louis, MO, USA, January 2006.

[28] V. P. Overschee and B. De Moor, Subspace identification for linear system, Kluwer Academic Publisher, Dordrecht, Netherlands, 1996.

[29] J. H. Yi and C. B. Yun, "Comparative study on modal identification methods using output-only information," Structural Engineering and Mechanics, vol. 17, no. 3-4, pp. 445-446, 2004.

[30] R. Brinker, L. Zhang, and P. Andersen, "Modal identification of output-only systems using frequency domain decomposition," Smart Materials and Structures, vol. 10, pp. 441-445, 2001.

[31] W. M. West, "Illustration of the use of modal assurance criterion to detect structural changes in an orbiter test specimen," in Proceeding of the International Modal Analysis Conference, Los Angeles, CA, USA, February 1986. 


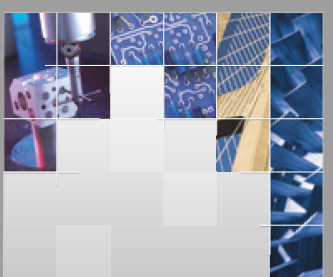

\section{Enfincering}
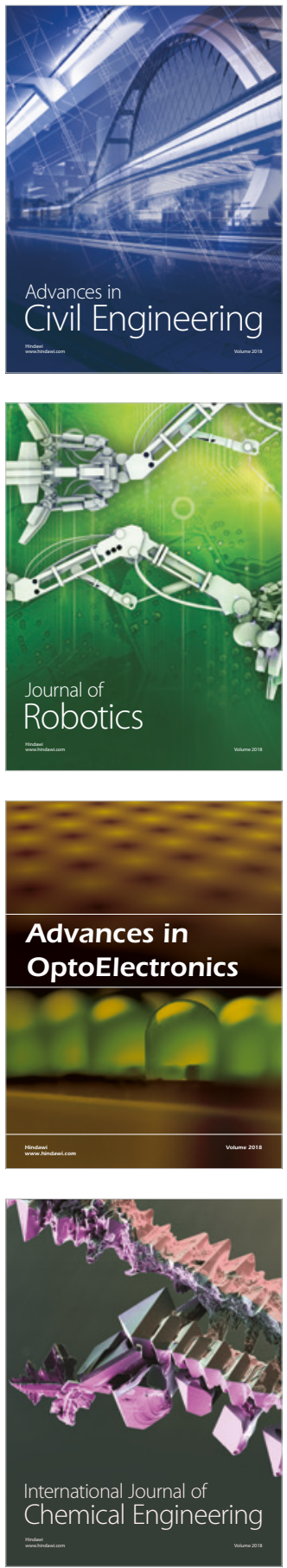

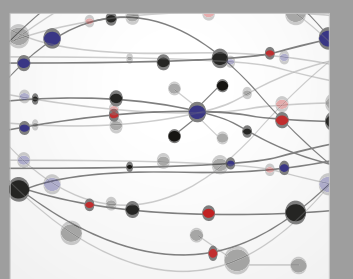

\section{Rotating \\ Machinery}

The Scientific World Journal

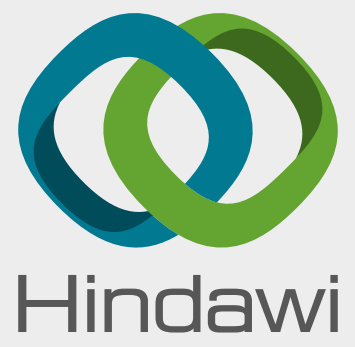

Submit your manuscripts at

www.hindawi.com
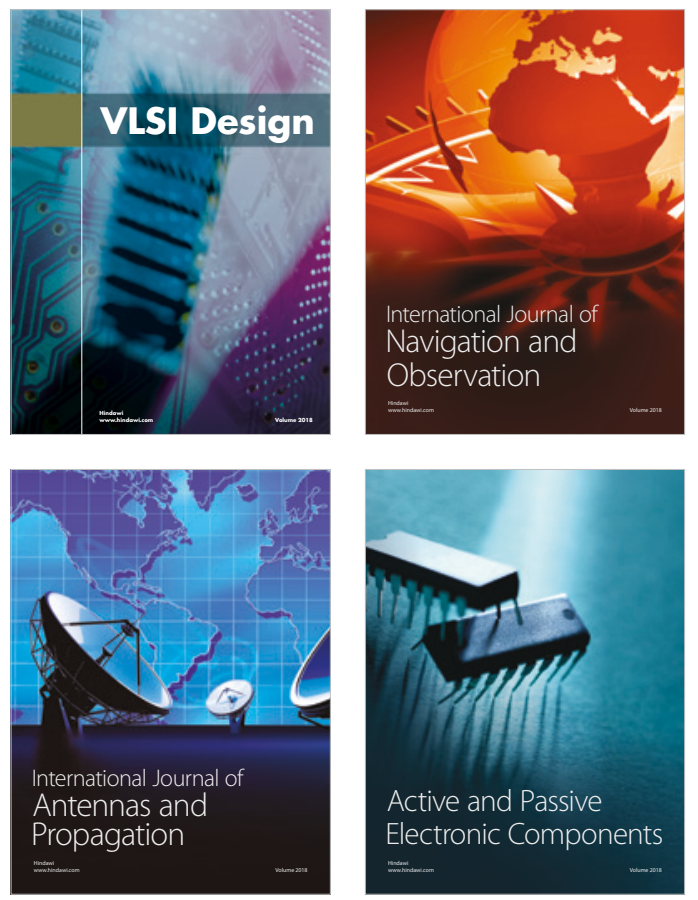
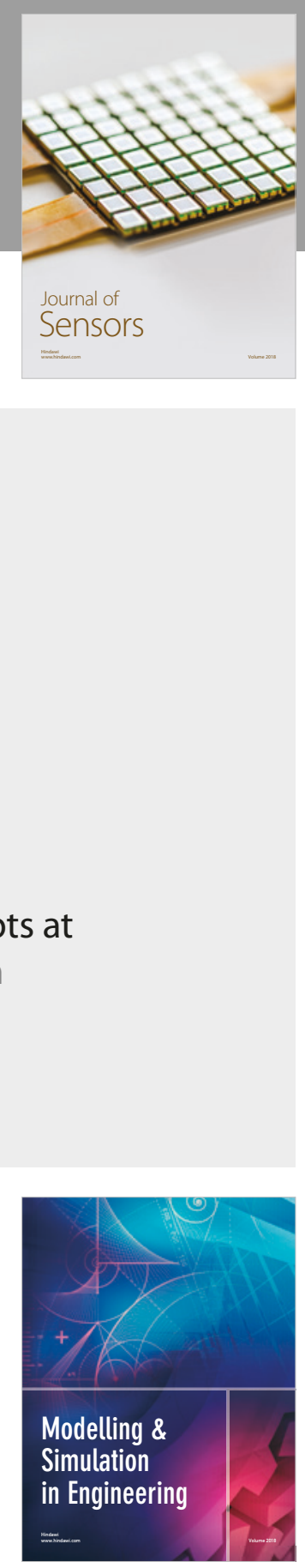

\section{Advances \\ Multimedia}
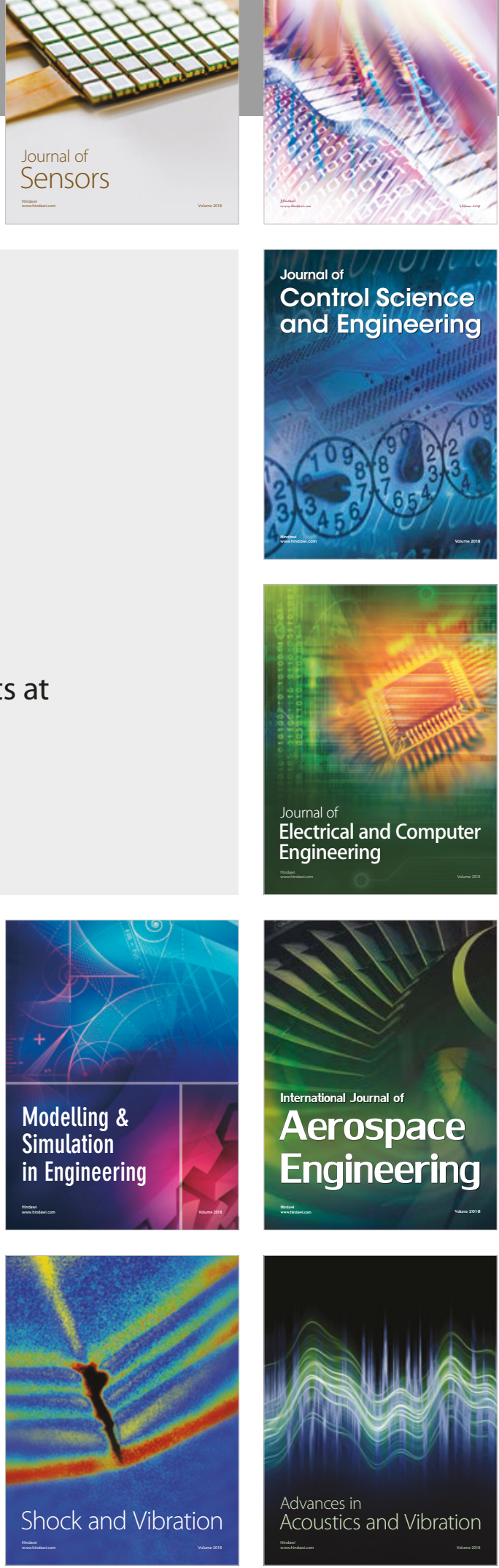